\title{
Chimeric chromosome landscapes of human somatic cell cultures show dependence on stress and regulation of genomic repeats by CGGBP1
}

\author{
Subhamoy Dattaㄹ, Manthan Patel ${ }^{1,2}$, Sukesh Kashyap ${ }^{1}$, Divyesh Patel ${ }^{1,3}$ and \\ Umashankar Singh ${ }^{1}$ \\ ${ }^{1}$ HoMeCell Lab, Discipline of Biological Engineering, Indian Institute of Technology Gandhinagar, Gandhinagar, Gujarat \\ 382355, India \\ ${ }^{2}$ Centre for Genomics and Child Health, Blizard Institute, Barts and The London School of Medicine and Dentistry, Queen \\ Mary University of London, London E1 2AD, UK \\ ${ }^{3}$ Current address: Research Programs Unit, Applied Tumor Genomics Program, Faculty of Medicine, University of Helsinki, \\ Biomedicum, Helsinki 00290, Finland
}

Correspondence to: Umashankar Singh, email: usingh@iitgn.ac.in

Keywords: CGGBP1; non-homologous chromosomal chimeras; methylation; heat stress; repeats

Received: November 08, $2021 \quad$ Accepted: December 20, $2021 \quad$ Published: January 17, 2022

Copyright: ( 2022 Datta et al. This is an open access article distributed under the terms of the Creative Commons Attribution License (CC BY 3.0), which permits unrestricted use, distribution, and reproduction in any medium, provided the original author and source are credited.

\section{ABSTRACT}

Genomes of somatic cells in culture are prone to spontaneous mutations due to errors in replication and DNA repair. Some of these errors, such as chromosomal fusions, are not rectifiable and subject to selection or elimination in growing cultures. Somatic cell cultures are thus expected to generate background levels of potentially stable chromosomal chimeras. A description of the landscape of such spontaneously generated chromosomal chimeras in cultured cells will help understand the factors affecting somatic mosaicism. Here we show that short homology-associated nonhomologous chromosomal chimeras occur in normal human fibroblasts and HEK293T cells at genomic repeats. The occurrence of chromosomal chimeras is enhanced by heat stress and depletion of a repeat regulatory protein CGGBP1. We also present evidence of homologous chromosomal chimeras between allelic copies in repeat-rich DNA obtained by methylcytosine immunoprecipitation. The formation of homologous chromosomal chimeras at Alu and L1 repeats increases upon depletion of CGGBP1. Our data are derived from de novo sequencing from three different cell lines under different experimental conditions and our chromosomal chimera detection pipeline is applicable to long as well as short read sequencing platforms. These findings present significant information about the generation, sensitivity and regulation of somatic mosaicism in human cell cultures.

\section{INTRODUCTION}

In somatic cells the randomly occurring mutations create mosaic patterns of different cell clusters representative of different genotypes, including some deleterious ones [1]. The mosaically occurring genomic variants arise out of errors in DNA metabolism, most likely due to the errors in replication and DNA repair. Mutagens and stressors that affect the fidelity of DNA replication and repair accelerate the emergence of genomic variants and add to the mosaicism. This process generates alternative genotypes stochastically and at low frequency.
In a population average of mosaic cellular genotypes, these, often single base changes and microsatellite variations, are diluted by the more consistently occurring inherited genotypes [2-4]. The mosaically occurring sequence variants can be segregated from the inherited genotypes by applying different statistical models $[5,6]$. The confidence in segregating inherited genotypes from mosaically occurring sequence variants can be enhanced by analysing the parental genotypes alongside the offspring's genotypes. The larger the population doublings the cells go through, the more diverse and complex the somatic mosaicism becomes. Thus, the somatic mosaicism 
in cultured cells, especially transformed or cancer-derived cell lines, is very difficult to decipher.

Somatic mosaicism, although often described in terms of sequence variants at single base positions, also consists of other kinds of genomic alteration, including chromosomal rearrangements, which undergo selection with time [7].

Chromosomal integrity is necessary for normal cellular functioning and chromosomal alterations not rectifiable by the DNA repair pathways are subject to selection or elimination. With some exceptions of natural changes in ploidy, the set of chromosomes normal for a cell is a constraint stabilized through evolution. Healthy development and differentiation depends on maintenance of the ploidy throughout countless cell divisions which is maintained as inherited in the somatic cells. Changes in the gross chromosomal composition, such as loss or gain of chromosome(s) as well as deletion or duplication pose a much larger challenge to cellular survival than single base changes and microsatellite variations $[8,9]$. Chromosomal rearrangements, unlike base changes, are not rectifiable by the DNA repair mechanisms and can only be eliminated by cell death or through their adverse effects on cell growth and division. As such, the somatic changes in chromosomal composition lead to erratic cell survival, proliferation and fuel clonal selection of mutant cells to drive tumorigenesis.

Somatically mosaic chromosomal aberrations have been widely described using microarray-based assays that detect copy number variations. Megabase-range deletion and loss of uniparental alleles are more common in somatic tissues than previously appreciated. Copy number variations (CNVs) can span $100 \mathrm{~kb}$ or longer and occur within protein coding genes [10]. CNVs can also include over $2 \mathrm{Mb}$ long copy-neutral loss of heterozygosity $(\mathrm{LoH})$, frequently seen in cancer cells and is affected by age [11-14]. Similar chromosomal micro-mosaicism (chromosomal mosaicism unidentifiable microscopically) also exists in healthy human tissues and by extension, in freshly isolated and cultured primary cells [15]. The actual mechanisms underlying such chromosomal micromosaicism have not been worked out. It is argued that unless inherited through the germline, such changes can occur through DNA repair pathways that involve breakage and ligation of double strand breaks. Other than xenobiotic mutagens that cause DNA strand breaks, what factors (i) accelerate the endogenous DNA damage leading to the strand breaks and (ii) misdirect the repair, remain poorly understood. The occurrence of $\mathrm{LoH}$ detected in kilobases to megabases long regions is also attributed only to these logical possibilities of double strand breaks or single strand breaks during replication followed by error-prone end-joining.

Somatic mosaicism is accelerated by environmental stressors [16]. Stressors can cause chromosomal fragmentation [17] and accelerate the large-scale genomic changes. Genome adaptation is a crucial factor in evolution under stresses of the environment [18]. Genomic rearrangements are needed for cell survival when the genome is under stress [19] and macromolecular damage and repair, most importantly that of DNA, guides the influence of stress on macromolecular reorganization, survival and evolution [20]. Stochastic genome alterations in response to environmental stressors is a major contributor to somatic mosaicism and occurs at a rate that is several orders of magnitude higher than that of the somatic point mutations $[9,21,22]$.

Heat stress induces DNA damage through impairment of repair mechanisms that seem to be evolutionarily conserved and it has been observed in cells of a variety of model systems [23-28]. Heat stress induces chromosomal aberration by compromising replication fork progression, impairment of DNA-protein interactions needed for repair and thus heat stressed S-phase cells exhibit more chromosomal instability than those in G1/ G2 [27, 29-31]. Heat induced DSBs are repaired by homologous recombination (HR) [32] and this process is inherently prone to error that gets exacerbated by heat stress [33-35].

Epigenetic changes can also add to somatic mosaicism [36]. Repeats are prominent sites of homologous recombination in human cells [37-39]. It has been reported that recombination of repeats [40] is mitigated by cytosine methylation [41-44]. In addition to repetitive sequences, the regions with high GC skew and $\mathrm{R}$-loop forming properties are also under tight epigenetic control and have been implicated in genomic instability through promiscuous recombinations [45-48].

Whether there are mechanisms, other than the DNA repair machinery, to mitigate the effects of environmental stressors and epigenetic instability on the somatic mutation load remains unexplored. The high throughput DNA sequencing datasets contain hidden, often ignored, information about the scale and nature of somatic mosaicism. The mosaicism at the level of DNA sequence can be highly variable across different sequencing platforms and hence difficult to establish. However, chromosomal micro-mosaicism can potentially be deciphered with higher confidence. The DNA sequence reads representing the sporadic chromosomal micro-mosaicism events are typically eliminated from data analysis steps as they fail to align to single chromosomes; a necessary condition in most cases. An additional challenge is posed by the presence of repetitive sequences, especially the interspersed repeats, in the DNA sequence reads representing chimeric chromosomes. Our recent works on the human protein CGGBP1 have involved large scale DNA sequence data analyses [49-54]. Since loss of CGGBP1 function has been shown to accelerate chromosomal fusions in cultured fibroblasts [55], the presence of chimeric chromosomal reads in our published sequencing datasets has remained 
an unexplored possibility. Interestingly, CGGBP1 is also a multifunctional protein [56] with roles in heat stress response [56, 57], epigenome homeostasis [50, 51, 53, 56, 57], regulation of repetitive sequences [49, 51, 52] and control of endogenous DNA damage [55].

Here, we have developed a DNA sequence data analysis strategy to reliably detect chimeric chromosomal events with high confidence. Through a step-wise pruning and manual curation of the sequence data we detect chimeric chromosomal events in normal human fibroblasts. We have applied this strategy to find out the effects of heat stress and CGGBP1 depletion on chimeric chromosome occurrence in genomic DNA of normal fibroblasts and HEK293T cells. We show that heat stress and CGGBP1 depletion give rise to chimeric chromosomes at regions with homologous sequences between different chromosomes. These regions are rich in L1 and satellite repeats. By applying a similar strategy based on variant calls in the published as well as newly generated cytosine methylation-enriched DNA sequence datasets, we show that CGGBP1 depletion increases interallelic chimeras as well. Our findings not only shed light on the extent of chromosomal micro-mosaicism prevalent in cell cultures rather also provide some insights into the underlying mechanisms. These findings are important for understanding somatic mosaicism, mutations and loss of heterozygosity.

\section{RESULTS}

\section{Widespread occurrence of non-homologous chromosomal chimeras in cultured human fibroblasts is enhanced by heat stress}

We set out to study the scale and nature of stable somatic mosaicism due to chromosomal fusions in cultured human cells. We sequenced the DNA from a human fibroblast line (Coriell Repository; GM02639, from the skin of a $19 \mathrm{yr}$ old male subject) (Supplementary Table 1), cultured at prescribed conditions, and established a strategy to detect and describe the non-homologous chromosomal chimeras. Our strategy (Figure 1A) involved the following steps in a series: (i) quality filtering of sequence reads, (ii) splitting of sequenced reads into nonoverlapping $0.2 \mathrm{~kb}$ bins, (iii) alignment of $0.2 \mathrm{~kb}$ fragments individually against hg38, (iv) curation of alignments to extract reads composed of fragments uniquely aligning only to two non-homologous chromosomes with the only unaligned fragment being the $0.2 \mathrm{~kb}$ bin in between (for example, alignments to chromosomes $\mathrm{A}$ and $\mathrm{B}$ with one unaligned bin $\mathrm{U}$ in between), (v) a single base sliding window unique alignment search to identify the region of transition between the two chromosomes on the chimeric sequence reads (A-U-B where $\mathrm{U}$ is the region between the regions aligning to $\mathrm{A}$ and $\mathrm{B}$ respectively), and (vi) classification of the region $\mathrm{U}$ with respect to its similarity to flanking regions of $\mathrm{A}$ and $\mathrm{B}$ (Figure 1A).

For $79.1 \%$ of reads, all the $0.2 \mathrm{~kb}$ fragments could be aligned to single chromosomes unambiguously. For $13.9 \%$ reads, at least one of the $0.2 \mathrm{~kb}$ fragments aligned to a different chromosome. Since the alignments were done on unmasked hg38, dual alignments of $0.2 \mathrm{~kb}$ segments could give rise to false positive chimeric events. Using the strategy described above (Figure 1A), we extracted the genuine A-U-B chimeric events from this population (13.9\%) of reads. The filtered set of A-U-B chimeric events were $1.5 \%$ of the total aligned reads (Table 1 and Supplementary Table 1). These events are referred to as "chromosomal chimeras". At 7\% reads, the alignments of $0.2 \mathrm{~kb}$ bins did not lead to identification of the reads as either non-chimeric or genuine A-U-B chimeric events and were eliminated from the analysis. Thus, we discovered that the chimeric chromosomes were prevalent in normal cells at stress-free culture conditions.

These cells are expected to have a normal karyotype. We thus interpreted that these non-homologous chromosomal chimeras represented a background load of errors generated sporadically in a small fraction of cells, akin to somatic mosaicism. We could verify that for each non-homologous chromosomal chimeric read detected through this method, there were on average $14.33 \pm 124.76$ reads (median $=2$ ) representing the two chromosomes with no chimeric event (Table 1). The high standard deviation in the number of non-chimeric chromosomal reads for each chimeric event is due to a non-uniform coverage of genomic regions in the sequence data. The background chimeric chromosome frequency (chimeric DNA events per billion bases sequenced) in these fibroblasts at $37^{\circ} \mathrm{C}$ (see methods), was 1078.69 (Table 1). This translated into just over a single transition to a non-homologous chromosome per 1 million bases sequenced.

Non-homologous chromosomal chimeras can occur spontaneously through error-prone non-homologous end-joining, mitotic recombination or a replication template switch between chromosomes. If true, then the occurrence of chromosomal chimeras would be affected by constraining cells to replicate and repair their DNA under conditions of stress. We used a heat shock regimen to study how heat stress affects the chimeric chromosomal landscape. We subjected the fibroblasts to heat shock by sequentially increasing the culture temperature by $1^{\circ} \mathrm{C}$ every $24 \mathrm{~h}$. Thus, the cells were observed for any visible signs of stress or cell death due to a cumulative exposure to the following temperatures: $38^{\circ} \mathrm{C}, 39^{\circ} \mathrm{C}, 40^{\circ} \mathrm{C}, 41^{\circ} \mathrm{C}$ and $42^{\circ} \mathrm{C}$ with a $24 \mathrm{~h}$ incubation at each temperature point (see methods for details). We deemed this duration as long enough for the cells to undertake DNA replication and/or repair. At the end of each cumulative heat stress temperature point, cells were also returned to $37^{\circ} \mathrm{C}$ for $24 \mathrm{~h}$ for recovery and resumption of paused DNA replication and repair. When returned to $37^{\circ} \mathrm{C}$ for a 


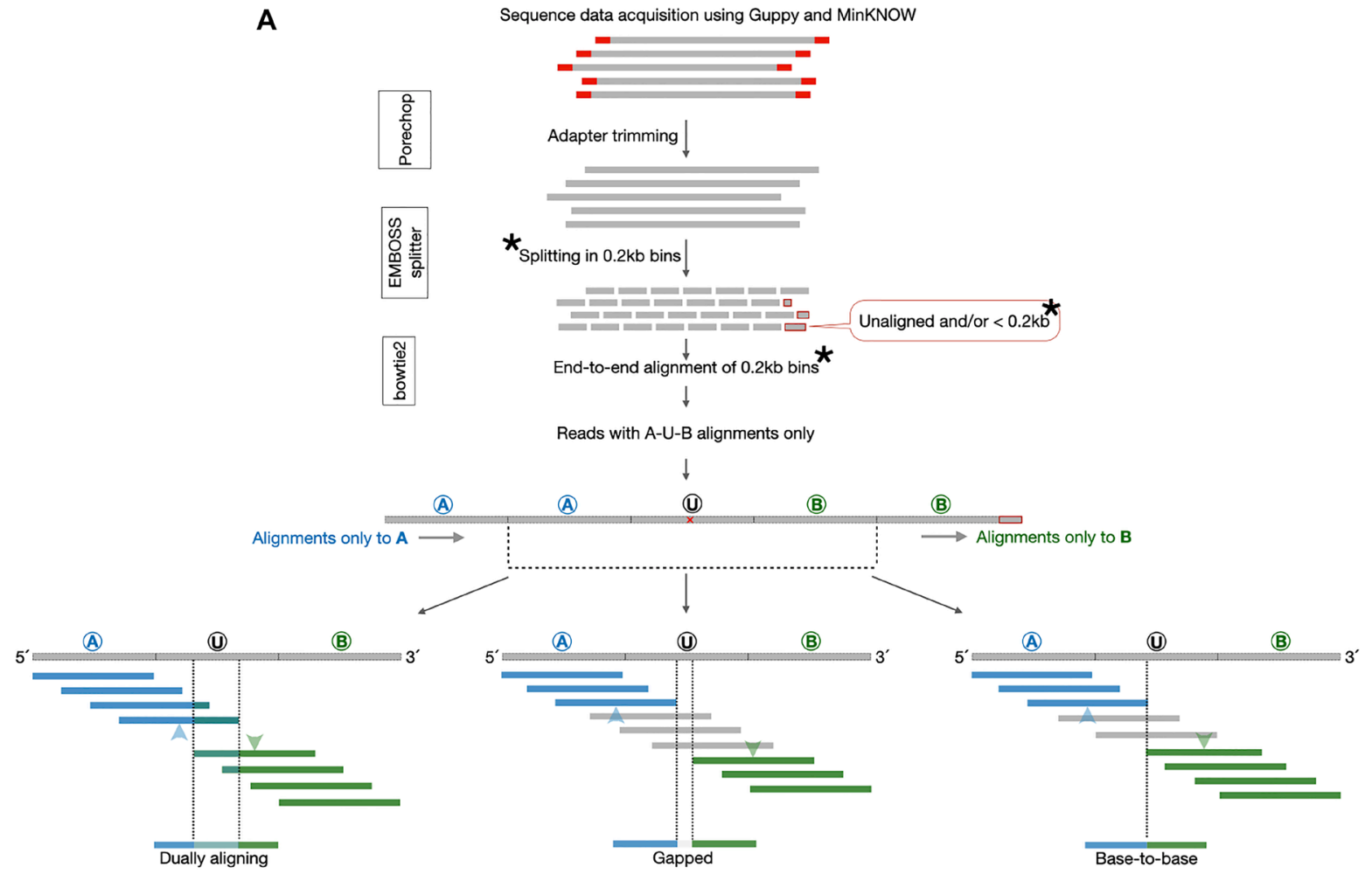

B

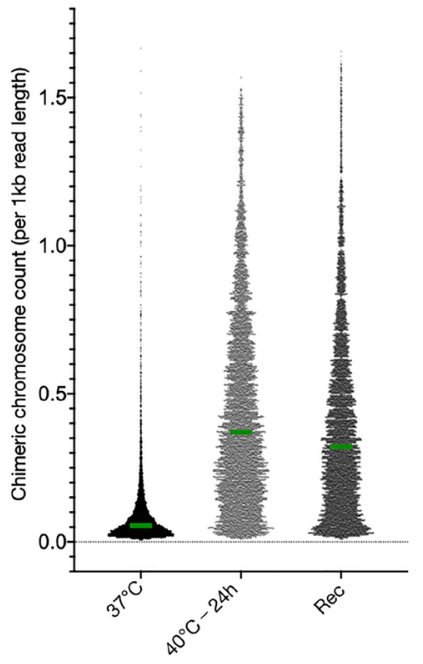

C

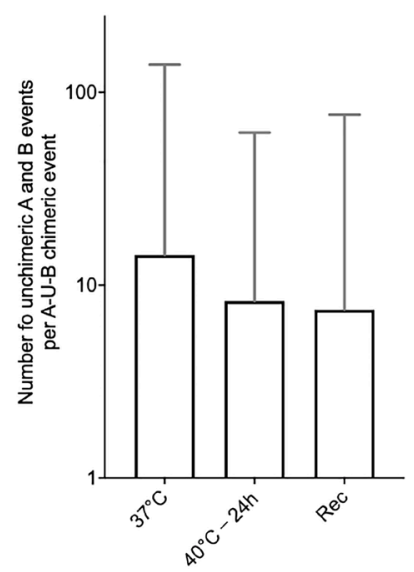

Figure 1: A curated analysis of genomic DNA sequence reads shows evidence of chimeric chromosomal DNA in normal cells that gets enhanced by heat stress. (A) DNA sequence reads were first run through quality check and adapter trimming and then split into end-to-end fragments of $0.2 \mathrm{~kb}$. Analysis was restricted to all the $0.2 \mathrm{~kb}$ long read fragments except for the ones at the 3 'end of the read which were smaller than $0.2 \mathrm{~kb}$ (as all the read-lengths were not multiples of $0.2 \mathrm{~kb}$ ). The $0.2 \mathrm{~kb}$ fragments were independently aligned to hg38. All the $0.2 \mathrm{~kb}$ fragments of a single reads were expected to align to only one and the same chromosome in hg38. Reads were extracted for which the $0.2 \mathrm{~kb}$ fragments aligned to only two different chromosomes with a single $0.2 \mathrm{~kb}$ bin serving as the transition point from one chromosome to the other. As shown, these reads were designated as A-U-B reads and the event was termed "occurrence of chimeric chromosomal DNA". The exact transition point within the $0.2 \mathrm{~kb}$ transition fragments were identified by a separate alignment exercise wherein $0.2 \mathrm{~kb}$ long fragments were aligned at a time with a single base shift from A towards B such that the shifting fragments alignments to $A$ transitioned to $B$. Moving from $A$ to $B$, the last $0.2 \mathrm{~kb}$ fragment aligning to $A$ and the first fragment aligning to $B$ are marked by blue and green arrowheads respectively. The various natures of the A-U-B events, dually aligning, base-to-base and gapped, are shown here. (B) The number of chimeric chromosomal DNA events observed in the $37^{\circ} \mathrm{C}$ sample were enhanced by heat stress in the sample $40^{\circ} \mathrm{C}-24 \mathrm{~h}$ and remained increased after recovery in the sample Rec (Unpaired $t$-test for all three sample pairs, $p<0.0001$ ). Green bars show the medians and all data points are plotted. (C) The identification of the chimeric chromosomal DNA events was not an artefact as for a vast majority of A-U-B events there were several non-chimeric A or B alignments observed. The $\mathrm{Y}$ axis values are mean $\pm \mathrm{SD}$. 


\begin{tabular}{lccc}
\hline \multicolumn{4}{c}{ Fibroblast (GM02639) sequencing details (data run through Porechop) } \\
\hline Sample Name & $\mathbf{3 7}^{\circ} \mathbf{C}$ & $\mathbf{4 0}^{\circ} \mathbf{C - 2 4} \mathbf{h}$ & $\mathbf{R e c}^{-}$ \\
\hline Total A-U-B chimeric events & 8633 & 15230 & 15868 \\
Chimeric DNA events per billion bases sequenced & 1078.69 & 3915.97 & 2208.68 \\
Number of non-chimeric reads per chimeric event (mean \pm SD) & $14.33 \pm 124.76$ & $8.27 \pm 53.45$ & $7.45 \pm 69.11$ \\
\hline
\end{tabular}

recovery from the varying amounts of heat stress, we first checked if the cells were able to survive or not. The maximum heat stress these cells could tolerate and yet remain adhered during recovery was $40^{\circ} \mathrm{C}$ for $24 \mathrm{~h}$ with only marginal loss of cells (not shown). We sequenced the DNA from two heat stressed samples, (i) $40^{\circ} \mathrm{C}-24 \mathrm{~h}$ and (ii) $40^{\circ} \mathrm{C}-24 \mathrm{~h}$ followed by recovery at $37^{\circ} \mathrm{C}-24 \mathrm{~h}$, and worked out the non-homologous chimeric chromosome landscape using the strategy described above for the $37^{\circ} \mathrm{C}$ sample. A comparison of the chimeric chromosomes detected per kilobase of read length in the three samples is shown in Figure 1 (Figure 1B). Clearly, the $40^{\circ} \mathrm{C}-24 \mathrm{~h}$ heat stress enhanced the occurrence of chromosomal chimeras whereas the $37^{\circ} \mathrm{C}-24 \mathrm{~h}$ recovery (Rec) resulted in only a partial reduction. These chimeric chromosome events were sporadic and a majority of chromosomal chimeras were represented by multiple non-chimeric DNA reads (Figure 1C). The non-chimeric reads to chimeric read ratio was decreased upon heat stress and did not reset after recovery (Figure 1C). These results indicated that some processes sensitive to heat stress are involved in the generation of non-homologous chromosomal chimeras. These chromosomal chimeras were also stable and not lost upon recovery from the heat stress.

\section{CpG-rich L1 and Alu repeats are the sites of spontaneous and heat-induced chromosomal fusions respectively in human fibroblasts}

Next we analyzed the sequence properties of the regions of chimeric transitions between different chromosomes (the $0.2 \mathrm{~kb}$ long region $\mathrm{U}$ in the A-U-B chimeric events). The chimeric events were distributed on the different chromosomes as expected from the chromosome sizes $(p<0.001$ for Pearson $r$ values $>0.5$ for correlations between all pairs of chromosomal fusions; Supplementary Figure 1). These regions did not show any significant DNA sequence motif enrichment or overlaps with the chromosomal fragile sites or disease-associated chromosomal fusion sites [58-61] (not shown)

To explain if DNA sequence properties predispose certain genomic regions to chromosomal fusions and generate chimeras, we explored the possibility that interspersed repeats could misdirect sequence homologybased DNA repair processes. A RepeatMasker search for repeat contents of the $U$ regions from the chimeras at $37^{\circ} \mathrm{C}$ showed that they were unusually rich in LINE1 repeats (40.21\% LINE-1 and 6.91\% Alu-SINEs).
Upon heat shock $\left(40^{\circ} \mathrm{C}-24 \mathrm{~h}\right)$, the chimeras occurred predominantly at LINE-1 but with an increase at Alu SINEs (25.87\% LINE-1 and 9.07\% Alu-SINEs). The abundance of chimeric events at repeat-free DNA was increased from $\sim 34 \%$ at $37^{\circ} \mathrm{C}$ to $\sim 46 \%$ at $40^{\circ} \mathrm{C}-24 \mathrm{~h}$ (Supplementary Table 2). Thus the chromosomes were susceptible to generate chimeras at LINE-1 repeats and heat stress enhanced chimeric events at repeat-free sites and Alu-SINEs.

During the heat stress, the misdirected homologybased strand invasions at Alu-SINE and LINE-1 repeats could facilitate strand annealing between non-homologous chromosomes which would mimic staggered double strand breaks but would not qualify as genuine chimeric DNA. Such strand annealing and staggered double strand breaks could get ligated to generate artefactual chimeric chromosomal DNA during sequencing library preparation that involves DNA end ligation. To establish the stability of the chromosomal chimeras generated upon heat stress, we allowed the cells to recover at $37^{\circ} \mathrm{C}$ for $24 \mathrm{~h}$; a condition sufficient to allow repair of unligated strand invasions. These chimeric chromosomal DNA could not be repaired at $37^{\circ} \mathrm{C}$ for $24 \mathrm{~h}$ and were detected post-recovery with the similar fraction of Alu-SINEs and LINE-1 as the heat-stressed sample without any recovery. The recovery simply reduced the chimeric events at repeat-free DNA from $46 \%$ to $40 \%$ with predominant prevalence of L1 repeats at the chimeric sites (32.41\% LINE-1 and 10.55\% Alu-SINEs). Thus, the events we detected as chimeric chromosomal DNA were likely bonafide fusions between two different chromosomal fragments (Supplementary Table 2).

A subfamily level analysis of the prevalence of AluSINEs and LINE-1 showed that the older subfamilies of these repeats were more prone to form chimeras upon heat shock (Supplementary Table 3). The AluS and L1M subfamilies accounted for the largest increase in chimeric events upon heat stress. The primate-specific LINE-1 subfamily L1P however remained the largest contributor of chimeric events at the U-bins (Supplementary Table 3).

The abundance of interspersed nuclear elements at the chimeric chromosomal sites posed several possibilities. There could be a crosstalk between the factors that regulate LINE-1 and Alu repeats and the events leading to the formation of chromosomal chimeras. Cytosine methylation and chromatin compaction act as barriers to recombination potential of the interspersed repeats prevalent in the human genome. We have recently 
Table 2: Details of repeat contents in the U-bins of the non-homologous chimeric events in GM01391-CT and GM01391-KD

\begin{tabular}{lcc}
\hline Samples & GM01391-CT & GM01391-KD \\
\hline Reads with chimeric events & 18809 & 30298 \\
Chimeric events per billion bases sequenced & 1217.64 & 1727.77 \\
\% Alu-SINEs in reads with chimeric events & 20.21 & 17.44 \\
\% LINE-1 in reads with chimeric events & 13.34 & 14.36 \\
\hline
\end{tabular}

described the cytosine methylation landscape in the same fibroblasts as the ones used here for the chimeric DNA identification. CGGBP1 has turned out to be a regulator of cytosine methylation at various subfamilies of Alu and LINE-1 elements [50, 51, 53]. The $0.2 \mathrm{~kb} \mathrm{U}$ bins of the chromosomal chimeras showed expected GC-richness $(\sim 40 \%)$, however, with a more than expected $\mathrm{CpG}$ content $(>1.25 \%$ for all the three samples) (Supplementary Table 4). We also observed a higher G/C-skew in the U regions of the $40^{\circ} \mathrm{C}-24 \mathrm{~h}$ DNA as compared to $37^{\circ} \mathrm{C}$ DNA (Supplementary Figure 2). G/C-skew is a property where cytosine methylation is prone to deregulation upon loss of function of CGGBP1 [50] as well as one which facilitates spurious chromosomal recombinations [48].

We next applied the chromosomal chimera detection pipeline to the already published MeDIP datasets from these cells [53]. This provided us with a possibility to answer multiple questions: What is the chimeric DNA landscape in DNA enriched for cytosine methylation and thereby also rich in repeats? Does CGGBP1 depletion affect generation of chromosomal chimera and if so, how? Can the chimeric chromosome detection pipeline be applied to IonTorrent sequencing reads with read lengths ranging around $0.2 \mathrm{~kb}$ ? We first analyzed our recently published MeDIP data and subsequently also generated new datasets in another fibroblast line to verify the findings.

\section{Chimeric chromosome analysis in MeDIP-DNA from adult human fibroblasts shows a restricted effect of CGGBP1 on chromosome Y-autosome chimeras}

The MeDIP-seq data from the fibroblast line (GM02639) was analyzed for evidence of chromosomal fusions. These MeDIP-seq data were generated on the IonTorrent platform with mean read length of approximately $0.2 \mathrm{~kb}$ using two samples, GM02639CT and GM02639-KD (GM02639-CT: CGGBP1-nontargeting siRNA; GM02639-KD: CGGBP1-targeting siRNA). We applied the same fusion detection pipeline as described above with one modification: the read fragmentation was done in units of $0.05 \mathrm{~kb}$ instead of $0.2 \mathrm{~kb}$ (the asterisk-marked step in Figure 1A).

As described for the heat stress experiments, first only the autosomal inter-chromosomal chimeras were analyzed. The chimeric chromosome frequency in GM02639-CT DNA was comparable to those detected in total genomic DNA using ONT platform with no increase observed in GM02639-KD (chimeric DNA events per billion bases sequenced in GM02639-CT and GM02639KD was 1217.64 and 1727.77 respectively; Table 2). The chimeric DNA events in the MeDIP samples showed a different repeat profile compared to the total genomic DNA. The Alu-SINEs repeat content was higher $(\sim 20 \%)$ than LINE-1 $(\sim 12 \%)$ and these values remained similar in CT and KD (Supplementary Table 5). These results showed that acute CGGBP1 depletion by siRNA does not enhance the net rate of chimeric chromosome generation at genomic regions rich in cytosine methylation. We could however apply our chimeric DNA detection strategy to short read sequence datasets (read length range 0.15 to $0.2 \mathrm{~kb}$ ) to detect chromosomal fusions with specificity.

These published male fibroblast MeDIP datasets were accompanied by sequence data from the parental genomes (GM02640 or paternal and GM02641 or maternal) allowing determination of allelic identities at thousands of locations genome-wide [53]. This provided an opportunity to detect chimeric chromosomal events between two different alleles and its dependence on CGGBP1. To detect the interallelic chimeric events between homologous chromosomes in the MeDIP data, the pipeline was applied with the following additions to the scheme used for non-homologous interchromosomal chimeras: (i) Each uniquely aligned read for the four samples (GM02639-CT, GM02639-KD, Maternal genomic, Paternal genomic) was subject to variant call with respect to the reference hg38. (ii) Variant locations were identified at which the parental genotypes allowed detection of allelic identities of the MeDIP-seq reads. These restricted combinations could be defined as locations where at least one parent had at least one unique allele (identifiable as a DNA sequence). Such unique parent-allele combinations would allow parent of origin annotations of the two alleles at the corresponding genomic locations in the MeDIP DNA from the offspring. (iii) MeDIP-seq reads from the offspring were classified as either maternal, paternal or having a single allelic transition (maternal to paternal or vice versa). (iv) The allelic annotations were curated to eliminate any reads which presented more than one switch between maternal and paternal identities based on the assumption that the read lengths were too small to present two allelic 
switches. Also, any offspring allelic identities which were different from the parental alleles were considered sporadic mutations or sequencing errors and eliminated. (v) The allelic recombination frequency was calculated as the percentage of total reads with unique parent-allele combinations which showed an allelic switch.

The variant calls, based on which the allelic identities of the reads were established, were mostly single nucleotide variants. Such variants can spontaneously arise in the culture and can interfere with actual parent-of-origin determination of DNA sequence reads. Before calculating the frequency of interallelic chimeric chromosomes, we first needed to establish the somatic mutation rate for CT and KD by segregating the expected genotypes from the unexpected genotypes. The availability of parental (Coriell Repository GM02640 and GM02641) genotypes for GM02639 [53] allowed us to calculate the rate of somatic point mutations.

In the absence of any somatic mutations, the GM02639-CT and -KD genotypes of the offspring are expected to be restricted and predictable by the parental genotypes. All the reads with such genotypes in GM02639-CT and -KD that were not expected from the parental genotypes were regarded as sequence changes due to random somatic mutations in culture, including some sequencing artifacts. Interestingly, over $50 \%$ of all the reads at which we could compare GM02639-CT and -KD MeDIP reads with parental reads, we found evidence of unexpected genotypes (Supplementary Table 6). Assuming that due to the somatic mutations any base $(\mathrm{A} / \mathrm{T} / \mathrm{G} / \mathrm{C})$ occurs on a single allele independently with a $25 \%$ probability, the probability of any base mutating to any of the three bases is $75 \%$ per allele and about $56 \%$ ( $75 \%$ of $75 \%$ ) on both the alleles at the same location. Thus, the observed $\sim 54 \%$ error rate of genotypes at diploid loci (autosomes) was expected. This calculation assumes that MeDIP enriches methylcytosine in the two samples without any net allelic bias. We also made use of the unique case of the maternal-derived $\mathrm{X}$ chromosome in the male fibroblasts to verify this mutation frequency. In line with the calculation above, for a monoallelic $\mathrm{X}$ chromosome, the observed maternal $\mathrm{X}$ genotypes were at nearly $25 \%$ of all the $\mathrm{X}$ chromosomal genotypes reported in CT and KD MeDIP-seq data (Supplementary Table 7). Thus, approximately $50 \%$ of the allelic recombinations identified in CT and KD MeDIP DNA would be due to somatic mutations.

The interallelic recombination frequency remained near 4\% in both GM02639-CT and GM02639-KD. After correcting for the somatic mutations, the allelic recombination frequencies in these $\mathrm{CT}$ and $\mathrm{KD}$ were $1.84 \%$ and $2 \%$ respectively (Supplementary Table 8 ). Thus, in these fibroblasts CGGBP1 depletion did not increase interallelic chimeras between homologous chromosomes, just like it had no effect on non-homologous chromosomal chimera. RepeatMasker analysis showed that the Alus or
LINEs contents occurred with expected percentage on the reads containing interallelic chimeras and showed no difference between CT and KD (Supplementary Table 9).

The absence of an allelic counterpart is expected to affect the rate at which the hemizygous chromosomes $\mathrm{X}$ and $\mathrm{Y}$ generate chimeras with the autosomes. Thus, the chimeras between autosomes and the chromosomes X or $\mathrm{Y}$ were analyzed separately. In CT, $5 \%$ of total chimeric reads were $\mathrm{X}$-U-autosome (X-U-A) chimeras. In $\mathrm{KD}$ this number was observed at $4.77 \%$ (Supplementary Table 10). Unlike chimeras between autosomes and the $\mathrm{X}$ chromosome, we observed a clear increase in Y-U-autosome (Y-U-A) chimera frequency upon CGGBP1 knockdown. Whereas $6.9 \%$ of reads mapping to the $\mathrm{Y}$ chromosome exhibited chimeras with autosomes in $\mathrm{CT}$, in $\mathrm{KD}$ the observed value was $9.36 \%$ (Supplementary Table 10).

With these results we concluded that our strategy can be applied to detect inter-allelic chimeric events specifically if parental sequence data is available. CGGBP1 depletion did not affect interchromosomal chimeric events either between non-homologous or homologous chromosomes in DNA enriched for methylcytosine. The GM02639 cells are from a 19 years old male subject. These cells are slow growing and respond to a partial CGGBP1 depletion by exhibiting a growth arrest. To validate these findings further, we needed to perform this analysis in normal cells which grow rapidly and do not exhibit a strong growth arrest upon partial CGGBP1 depletion.

\section{Chimeric chromosome prevalence in MeDIP- DNA of a female infant's fibroblast shows a strong dependence on CGGBP1 depletion}

The heat stress experiments described above suggested that the chromosomal fusions arise due to cellular growth processes, including replication and DNA repair errors, under stress. The growth arrest and inertness of these cells, especially upon CGGBP1 depletion, could under-represent the changes in chromosomal fusion frequency in KD. Thus, we replicated these experiments in rapidly growing normal fibroblasts that would continue at least some replication and repair of DNA upon CGGBP1 knockdown. We selected a normal fibroblast line from a 9-month old female (Coriell Repository GM01391) for which parental fibroblasts were available as well. These cells showed a much higher rate of proliferation than the GM02639 fibroblasts (not shown). GM01391-CT and GM01391-KD samples were generated in these cells using the same protocols of siRNA transfection followed by MeDIP-seq, as described before (Supplementary Figure 3). The choice of a female cell line also eliminated the challenges posed by hemizygosity of sex chromosomes in characterization of interchromosomal chimeras.

The non-homologous interchromosomal chimeras in CT were at 1217.64 per billion bases sequenced, which rose 1.4 fold to 1727.77 in KD (Table 2 and 
Table 3: X-U-A chimeric events in GM01391-CT and GM01391-KD

\begin{tabular}{lcc}
\hline Samples & GM01391-CT & GM01391-KD \\
\hline Reads mapped & 67725152 & 80980111 \\
Reads mapped on X chromosome & 3230110 & 2263810 \\
\% mapped reads on X chromosome & 4.77 & 2.80 \\
Reads with X-U-A chimera & 1458 & 1625 \\
\% X-U-A chimera (observed) & 7.75 & 5.36 \\
\% X-U-A chimera (expected) & 7.75 & 3.14 \\
\hline
\end{tabular}

Table 4: Interallelic chimeras detected on autosomes and $X$ chromosomes in GM01391-CT and GM01391-KD

\begin{tabular}{lcccc}
\hline Samples & GM01391-CT & GM01391-KD & GM01391-CT & GM01391-KD \\
\hline Chromosomes & \multicolumn{2}{c}{ Autosomes } & \multicolumn{2}{c}{ X chromosomes } \\
\hline Reads with only maternal allelic identity & 2053554 & 940277 & 91118 & 20649 \\
Reads with only paternal allelic identity & 2376579 & 1002715 & 71182 & 11238 \\
Reads with interallelic chimeras & 75879 & 108513 & 2244 & 2083 \\
Total reads & 4506012 & 2051505 & 164544 & 33970 \\
\% Reads with interallelic chimeras & 1.68 & 5.29 & 1.36 & 6.13 \\
\% Reads with interallelic chimeras (corrected & 0.69 & 2.50 & 0.56 & 2.90 \\
for somatic mutation rate) & & & & \\
\hline
\end{tabular}

Supplementary Table 11). The repeat content of the reads exhibiting chimeric events were $20.21 \%$ Alu-SINEs and $13.34 \%$ LINE-1 in CT and $17.44 \%$ Alu-SINEs and $14.36 \%$ LINE-1 in KD (Table 2).

To calculate the fusions between the $\mathrm{X}$ chromosome and autosomes, we first needed to establish if our MeDIPseq actually captured $\mathrm{X}$ chromosomal DNA equally in $\mathrm{CT}$ and $\mathrm{KD}$. In $\mathrm{CT}$ and $\mathrm{KD}$, the fraction of total MeDIPseq reads aligning to the $\mathrm{X}$ chromosome were $4.77 \%$ and $2.80 \%$ respectively (Table 3 ). The representational bias against the $\mathrm{X}$ chromosome in MeDIP-seq would thus affect the detection of X-U-A chimeric events. We hence calculated the expected $\mathrm{X}$-autosome chimeric events by normalizing the $\mathrm{X}$ chromosomal read counts in $\mathrm{CT}$ and KD. Against an expected 3.14\% (due to a lower capture of $\mathrm{X}$ chromosome in $\mathrm{KD}-\mathrm{MeDIP}$ as compared to CT-MeDIP), we observed that $5.36 \%$ of reads mapping to the $\mathrm{X}$ chromosome represented chimeras with the autosomes. In CT, the X-U-A chimeric events remained at $7.75 \%$ (Table 3). Thus, despite a near 50\% decrease in the representation of $\mathrm{X}$ chromosome in the MeDIPseq, the frequency of X-U-A chimeras increased upon CGGBP1 depletion. These findings suggested that in the background of unequal cytosine methylation capture of the $\mathrm{X}$ chromosome between $\mathrm{CT}$ and $\mathrm{KD}$, there was an increase in the rate at which the $\mathrm{X}$ chromosome formed chimeras with autosomes upon CGGBP1 depletion. This effect of differential enrichment of X chromosome in MeDIPseq however would be inconsequential for interallelic $\mathrm{X}$ chromosomal fusion events.
The somatic mutation rate was calculated for GM01391 MeDIP-seq data by comparing the CT and KD genotypes with those of the parental cells and calculating the expected and unexpected genotype frequencies. The mutation rates calculated for $\mathrm{CT}$ and $\mathrm{KD}$ conformed to the same rates as calculated for the son earlier and ranged at $59.08 \%$ and $52.66 \%$ respectively (Supplementary Table 12). We observed that upon CGGBP1 depletion, the autosomal interallelic chimeric events were increased significantly. In CT, the interallelic chimeras were detected at $1.68 \%$ ( $0.69 \%$ after correction for somatic mutations) of all the reads aligning to the autosomes at locations where the parental genotypes were unique to decipher allelic identities. This increased to $5.29 \%$ (2.50\% after correction for somatic mutations) in KD (Table 4). Unlike the interchromosomal chimeric reads, the interallelic chimeric reads did not show any unexpected repeat content with no change upon CGGBP1 depletion. Similar to the autosomes, on the $\mathrm{X}$ chromosome also we observed a strong increase in interallelic chimeras. The $\mathrm{CT}$ interallelic chimera frequency of $1.36 \%(0.56 \%$ after correction for somatic mutations) was increased to $6.13 \%(2.90 \%$ after correction for somatic mutations) in KD (Table 4). The coordinates of the interchromosomal chimeric DNA events are listed in the GSE169435.

These results suggested that in a juvenile fibroblast line, the depletion of CGGBP1 indeed enhanced formation of chimeric chromosomes. This enhancement of chromosomal fusions due to CGGBP1 depletion was weaker at inter-chromosomal chimeras, which were 
Table 5: Gene bodies containing interallelic chimeras in GM02639-CT, GM02639-KD, GM01391CT and GM01391-KD

\begin{tabular}{lcc}
\hline Samples & Coverage on gene bodies (observed) & Coverage on gene bodies (expected) \\
\hline GM02639-CT & 5113 & 10273 \\
GM02639-KD & 3980 & 10507 \\
GM01391-CT & 2757 & 14796 \\
GM01391-KD & 5830 & 16486 \\
\hline
\end{tabular}

associated with more than expected Alu repeats. However, the interallelic chimeras, formed between the homologous chromosomes, were not associated with unexpected amounts of Alu repeats, occurred at a higher frequency and were strongly enhanced by CGGBP1 depletion.

\section{Inherent resistance against formation of interallelic chimeras within gene bodies is compromised by CGGBP1 depletion}

The detection of interallelic chimeras in the MeDIPseq data was limited only to the regions where the parental genotypes allowed parent-of-origin identification in the offspring. The sporadic nature of these chimeric events is revealed by the following statistics: Overall, the number of non-chimeric reads for every interallelic chimeric event in the male fibroblast was 23.4 for $\mathrm{CT}$ and 21.9 for $\mathrm{KD}$. In the female fibroblast however, the overall representation of non-chimeric reads for each interallelic chimeric event was 58.4 in CT and 17.9 in KD (Supplementary Table 13).

Allelic recombination in somatic cells can be deleterious as they can result in $\mathrm{LoH}$ of genes. We next analyzed if the interallelic chimeric events were occurring randomly throughout the genome and to what extent did they occur within the gene bodies. The coverage of the MeDIP-seq reads showing interallelic chimeras within gene bodies was determined. A normalized set of reads (to eliminate any sequencing depth biases between the samples) were randomly selected from each sample for this coverage analysis. The coverage counts were thus obtained for the entire set of genes (UCSC known transcripts) under two conditions: the "observed" wherein the locations of the interallelic chimeric events were as reported by MeDIP-seq analysis, and, "expected" wherein the same locations were randomly reshuffled throughout the genome (Supplementary Table 14). This expected versus observed analysis showed that, if the allelic chimeras were forming at random locations genome-wide, they would have occurred in over $10 \mathrm{~K}$ and $14 \mathrm{~K}$ known transcripts in male and female respectively (Table 5 and Supplementary Table 14). The observed coverage counts for $\mathrm{CT}$ and $\mathrm{KD}$ in the male fibroblast were 5113 and 3980 respectively. In the female data, the coverage counts were increased from 2757 in CT to 5830 in KD (Table 5 and Supplementary Table 14). These data show that the sporadically occurring allelic recombination is non-random in its genomic localization and it occurs at a rate much lower than randomly expected. There seems to be a paucity of interallelic chimeric events within the known genes. In the female fibroblast, which was more responsive to CGGBP1 depletion, we could observe that depletion of CGGBP1 accelerated the otherwise restrained interallelic chimeric events within gene bodies. The coordinates of the interallelic chimeric DNA events are listed in the GSE169435.

These results collectively suggested that chimeric DNA is formed in cultures cells at a background rate that is enhanced by heat stress and CGGBP1 depletion. The MeDIP-seq experiments were conducted in fibroblasts with only a partial (approximately 50\%) depletion of CGGBP1. The effect of CGGBP1 depletion was especially pronounced in rapidly growing cells from an infant. The chromatin functions of CGGBP1 have been studied in HEK293T cells. The proliferation of these cells is refractory to CGGBP1 depletion and they make a good system to study the effects of CGGBP1 depletion. We next used the HEK293T stable CT and KD cells for studying the chimeric DNA profiles with or without heat stress.

\section{Depletion of CGGBP1 mimics the effect of heat stress on chromosomal fusions in HEK293T cells}

We have recently reported the effects of CGGBP1 depletion in HEK293T using stable expression of CT (control non-targeting shRNA) and KD (CGGBP1targeting shRNA). The KD cells have been selected to grow with a $>95 \%$ knockdown of CGGBP1 [49]. However, the effects of heat stress on chromosomal fusions in these cells is not reported. We first determined the maximum tolerated heat stress for HEK293T-CT and -KD cells. By combining heat stress with HEK293T-CT and -KD we could study how heat stress and CGGBP1 depletion cooperate to generate similar patterns of chromosomal chimeras.

HEK293T-CT and -KD both exhibited high A-U-B type interchromosomal chimeric events per billion bases sequenced (Table 6) at $37^{\circ} \mathrm{C}$ which were marginally increased in $\mathrm{CT}$ and decreased in $\mathrm{KD}$ due to heat stress of $42^{\circ} \mathrm{C}$ for $24 \mathrm{~h}$ (RM one-way ANOVA on total values of fusions per billion bases yield a $P$ value of 0.0487 and $F$ value 14.87; Figure 2A). Recovery of heat-stressed HEK293T-CT (Rec) and -KD (Rec) 
Table 6: Sequencing details and A-U-B chimeric events at $37^{\circ} \mathrm{C}, 42^{\circ} \mathrm{C}-24 \mathrm{~h}$ and $\mathrm{Rec}$ in $\mathrm{HEK} 293 \mathrm{~T}-$ CT and HEK293T-KD

\begin{tabular}{|c|c|c|c|c|c|c|}
\hline \multicolumn{7}{|c|}{ Sequencing details of HEK293T-CT and HEK293T-KD (data run through Porechop) } \\
\hline \multirow{2}{*}{ Sample name } & \multicolumn{3}{|c|}{ CT } & \multicolumn{3}{|c|}{ KD } \\
\hline & $37^{\circ} \mathrm{C}$ & $42^{\circ} \mathrm{C}-24 \mathrm{~h}$ & Rec & $37^{\circ} \mathrm{C}$ & $42^{\circ} \mathrm{C}-24 \mathrm{~h}$ & Rec \\
\hline Read count & 3466514 & 4498601 & 4854367 & 1520137 & 2771387 & 3455586 \\
\hline Base count & 7363547914 & 11125962251 & 4775769144 & 5950672728 & 8705948759 & 5631750380 \\
\hline Mean read length & 2124.19 & 2473.2 & 983.81 & 3914.56 & 3141.37 & 1629.75 \\
\hline Reads mapped by bowtie2 & 2686403 & 3719299 & 3130809 & 1314196 & 2456097 & 2471051 \\
\hline$\%$ mapped reads & 77.50 & 82.68 & 64.49 & 86.45 & 88.62 & 71.51 \\
\hline Total A-U-B chimeric events & 16131 & 26614 & 37404 & 19074 & 27653 & 35325 \\
\hline $\begin{array}{l}\text { Chimeric DNA events per } \\
\text { billion bases sequenced }\end{array}$ & 2190.66 & 2392.06 & 7832.04 & 3205.35 & 3176.33 & 6272.47 \\
\hline
\end{tabular}

samples at $37^{\circ} \mathrm{C}$ caused significant cell death along with an increase in chimeric events per billion bases sequenced (Supplementary Figure 4 and Table 6). Further analyses of chimeric DNA events in HEK293T-CT and -KD were restricted to $37^{\circ} \mathrm{C}$ and $42^{\circ} \mathrm{C}-24 \mathrm{~h}$ samples only. The chimeric events from these samples showed a genome-wide distribution as expected according to the chromosomal lengths $(p<0.001$ for Pearson $r$ values $>0.5$ for correlations between all pairs of chromosomal fusions; Supplementary Figure 5). There were no obvious regional differences within each chromosome for the chimeric events in CT and KD (Supplementary Figure 6). The reads representing the chimeric events were rare and embedded within the majority of non-chimeric reads in the same regions (Supplementary Figure 7).

Next, we characterized the nature of these CT and KD chimeric events. The chimeric events were more prevalent in regions with higher $\mathrm{G} / \mathrm{C}$-skew (Supplementary Figure 8). Using a single base window, sliding $5^{\prime}$ to $3^{\prime}$ from chromosome A to B on each A-U-B read, $0.2 \mathrm{~kb}$ fragments were generated (Figure $2 \mathrm{~B}$ ) and subjected to alignments. In all the samples the $\mathrm{U}$ bins of the majority of chimeric events aligned to both the chromosomes A and B. Most of these dually aligning sequences (Figure 2B) were either exact base-to-base transition points or with short homology (20 to 60 bases long) between A and B. These chimeric events with dually aligning $U$ bins were elevated by heat shock as well as CGGBP1 depletion with only a marginal additive effect of the two treatments (Figure 2B). The less frequent gapped chimeric events, where the $\mathrm{U}$ bin sequences did not align to chromosome $\mathrm{A}$ or $\mathrm{B}$, did not increase upon heat stress in $\mathrm{CT}$ as well as KD (Figure 2B). Representatives of the three different types of chimeric events are shown in Figure 2 (Figure 2C). Unlike the short homology events, the frequency of the gapped events were independent of CGGBP1 depletion. For comparison, the short homology events were significantly CGGBP1-dependent (Chi-square 15.78, df 1, z 3.972, $P$ value $<0.0001$; Figure $2 \mathrm{~B}$ ). The gapped chimeric events showed no significant CGGBP1-dependence (Chi-square 0.4091 , df 1 , z $0.6396, P$ value 0.5224 ).

Short sequence homologies could occur at repeats and so the repetitive sequences could be a target of such short homology chimeric events. We found that heat stress in CT increased short homology chimeric events strongly at LINEs and simple repeats with moderate increases at Alu and repeat-free regions (Figure 2D-2G; ANOVA test details in Supplementary Table 15). Overall, the increases in short homology chimeric events due to CGGBP1 depletion matched (LINEs and simple repeats) or exceeded (Alu and repeat-free sequences) those due to heat stress (Figure 2D-2G). CGGBP1 depletion mimicked the increase in short homology chimeric events caused by heat stress most strongly at LINEs and simple repeats. A combination of CGGBP1 depletion and heat stress did not have an additive effect suggesting that the short homology fusions caused by heat stress involve a deactivation of CGGBP1 (Figure 2D-2G). The coordinates of the fusion events are listed in the GSE169435.

\section{Enhanced TP53BP1 marks the repeat-rich chromosomal fusion sites induced by CGGBP1 depletion}

We have previously described the role of CGGBP1 in heat shock response, endogenous DNA damage and chromosomal fusions independently. Our findings suggested that CGGBP1 depletion and heat stress induce short homology-directed chromosomal rearrangements through overlapping mechanisms that might involve misdirected DNA repair at repeats. TP53BP1, a marker of DNA damage and repair, facilitates recombinational repair [62]. We asked if the formation of short homology chimeric sequences, seemingly caused by CGGBP1 depletion and heat stress through overlapping mechanisms, indeed involved CGGBP1-dependent DNA repair marked by TP53BP1. We performed ChIPseq for TP53BP1 in CT and KD (sequence data details 

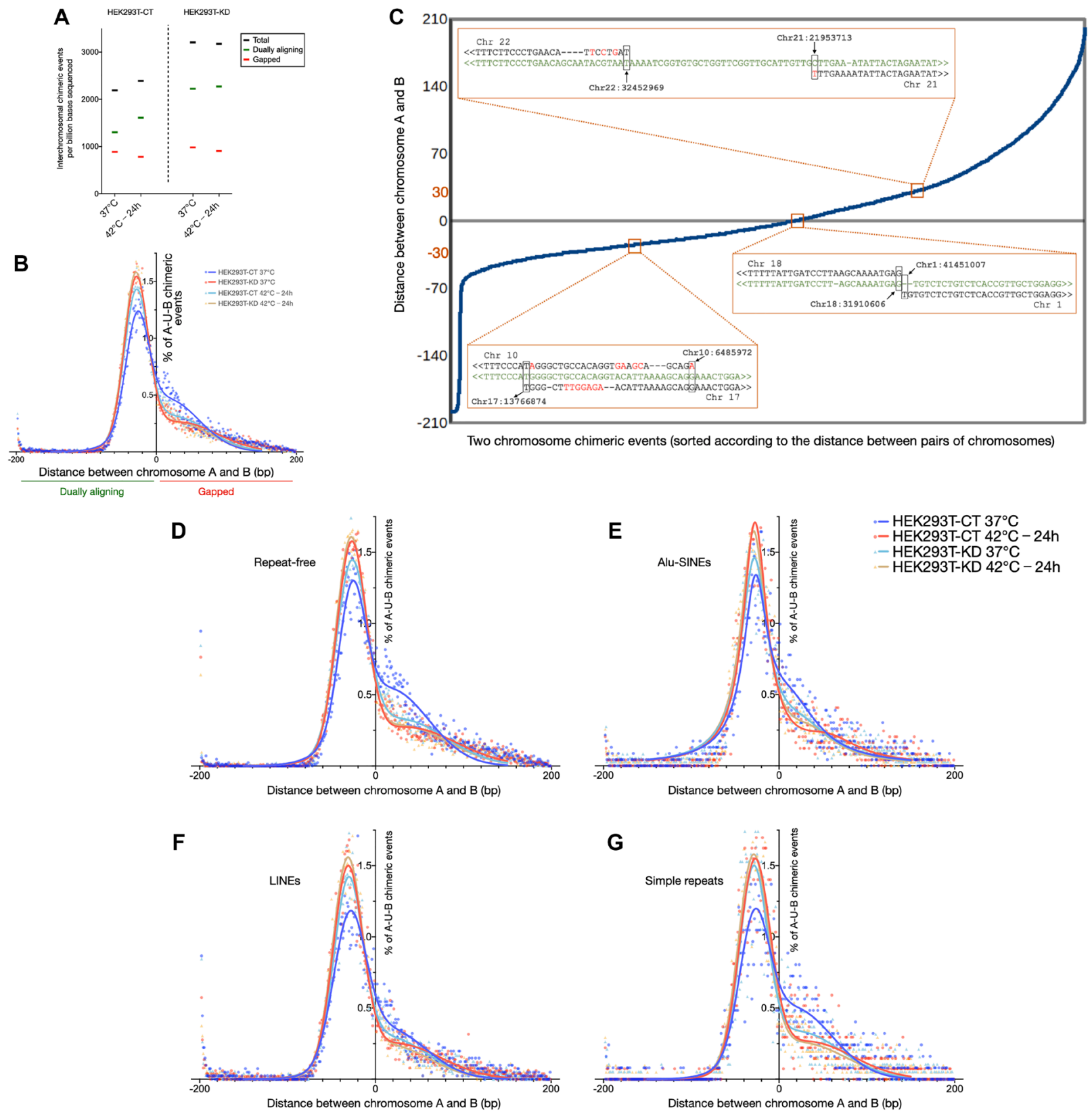

Figure 2: Depletion of CGGBP1 mimics the effects of heat stress on chimeric chromosomal DNA formation in HEK293T cells. (A) The number of chimeric chromosomal DNA events observed per billion bases sequences sequenced in HEK293T cells shows that the chimeric events are enhanced by CGGBP1 depletion as well as heat stress (black data points). The dually aligning chimeric events (green data points) accounted for the increase in the chimeric events in HEK293T-CT $40^{\circ} \mathrm{C}-24 \mathrm{~h}$ and HEK293T-KD samples compared to that in the HEK293T-CT $37^{\circ} \mathrm{C}$ sample. Remarkably, heat stressing the HEK293T-KD sample did not further enhance the chimeric DNA events. The gapped chimeric events (red data points) showed no increase upon heat stress or CGGBP1 depletion. (B) A comparison of the frequency of gapped or dually aligning chimeric events in the same samples as shown in (A). The X-axis shows the gap between the last $0.2 \mathrm{~kb}$ fragment of the $\mathrm{U}$ bin aligning to $\mathrm{A}$ and the first $0.2 \mathrm{~kb} \mathrm{U}$ bin aligning to $\mathrm{B}$. Negative values depict dually aligning chimeric events, positive values depict gapped events and zero depicts a base-to-base juxtaposition of $\mathrm{A}$ and $\mathrm{B}$ in the $\mathrm{U}$ bin. The Y-axis shows the percent of chimeric events. The first major peak of a double Guassian fit of the frequency distribution shows that the dually aligning events are the least in HEK293T-CT $37^{\circ} \mathrm{C}$ (blue data points) sample and similarly increased upon heat stress and/or CGGBP1 depletion (aqua, orange and red data points). Such a change was not observed in the gapped alignments. (C) Examples of sequence alignments of the reads at the $\mathrm{U}$ bin against the chromosomes A and B. The read sequences are in green, chromosomal genomic sequences are in black with gaps in the alignments shown as "-" and mismatches shown in red. (D-G) The events shown in (B) when split according to repeat contents in their U bin containing the chimeric event show that the effect of CGGBP1 depletion and heat stress in increasing dually aligning chimeric events is maximal at $\mathrm{U}$ bins containing no repeats (D) and Alu-SINEs (E) containing $\mathrm{U}$ bins show a weak effect of heat stress and/or CGGBP1 depletion on chimeric DNA occurrence. In contrast, the U bins containing LINE (F) and simple repeats (G) showed increased dually aligning chimeric events upon CGGBP1 depletion and/or heat stress. 
in Supplementary Table 16). The data analysis pipeline is described in Supplementary Figure 9. The fraction of unaligned reads that could potentially be from repetitive regions and account for chimeric events was higher in KD compared to CT (Supplementary Table 16). When we extracted the A-U-B events from TP53BP1 ChIP-seq data, we found a staggering amount of Alu-SINEs content

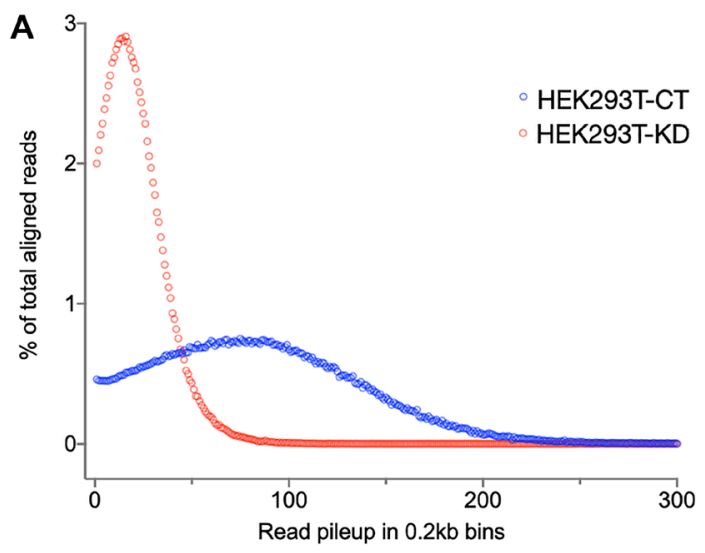

(43\% in CT and 29\% in KD) (Supplementary Table 17). In CT, TP53BP1 occupancy was restricted to fewer regions with higher coverage per region whereas in KD the TP53BP1 occupancy was spread out with low coverage throughout the genome (Figure 3A). Thus, the focussed and specific TP53BP1 occupancy in CT was disrupted in $\mathrm{KD}$ (Figure 3B). Despite a dispersed redistribution
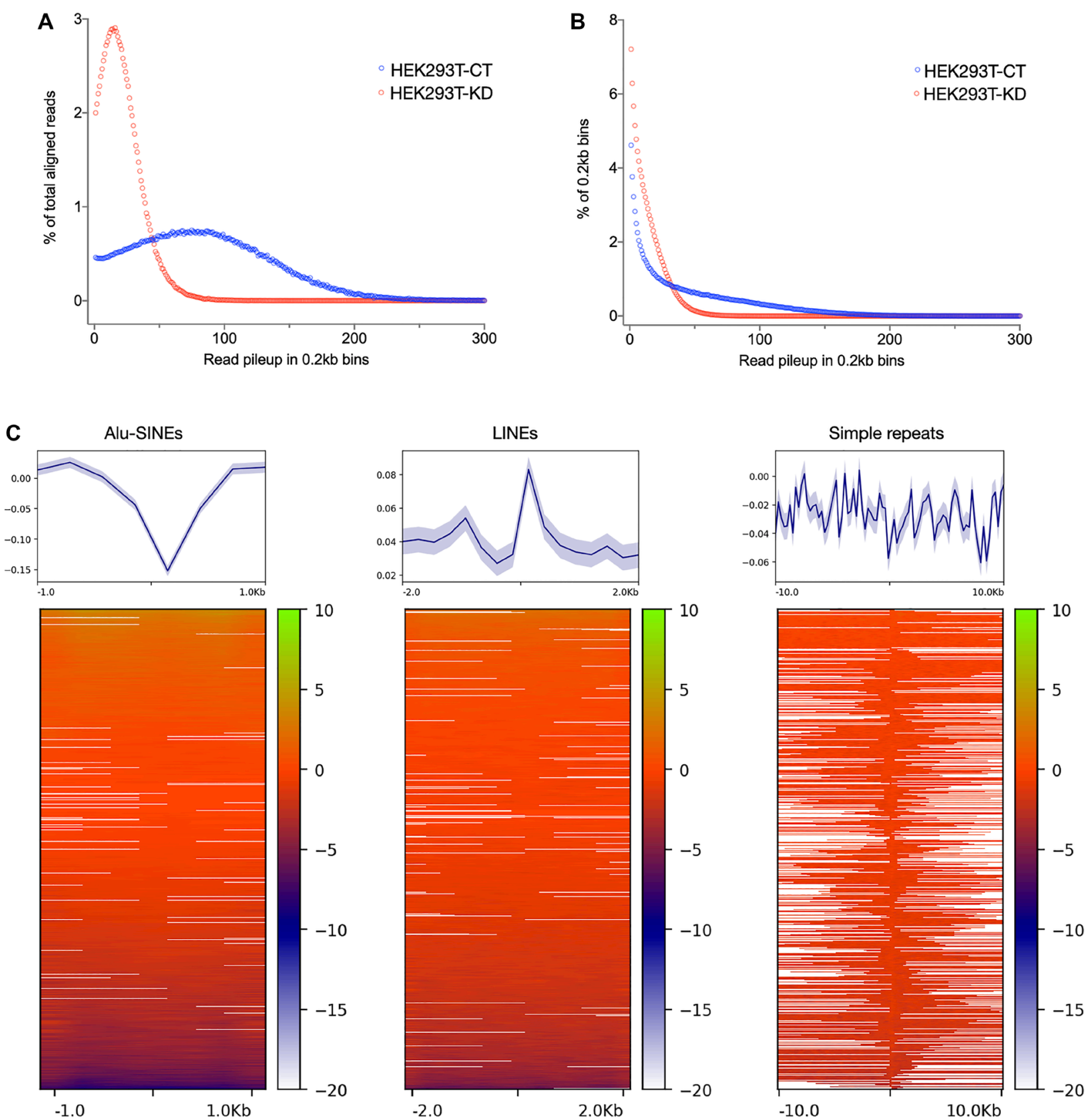

Figure 3: TP53BP1 occupancy change upon CGGBP1 depletion suggests disruption in genomic integrity in the flanks of repeats: (A and B) TP53BP1 ChIP-sequencing reads in HEK293T-CT show a distribution of read pileup peaking around 70-100 (X-axis values for the blue sample in A). Upon CGGBP1 depletion, the peak of read pileup in HEK293T-KD shifts to around 20 (X-axis values for the red sample in A). Accordingly, a majority of HEK293T-KD reads belonged to low read pileups (red sample in B) as compared to HEK293T-CT in which there was a higher prevalence of reads in high read pileup. These results suggest that the TP53BP1 occupancy that is concentrated at a smaller number of genomic sites is diluted and dispersed onto multiple sites genome-wide. (C) The change in TP53BP1 occupancy, calculated as a normalized signal difference HEK293T-CT - HEK293T-KD, shows that TP53BP1 occupancy is enhanced in the flanks of repeat sequences, with the strongest effects observed in the flanks of LINEs and simple repeats, the same repeats at which dually aligning chimeric events are concentrated. The plots in the top panel show mean with standard error. 
of TP53BP1, Alus remained the most prominent repeat content in the A-U-B chimeric events where TP53BP1 was bound in close vicinity (read length 150-200 bps; sonicated input DNA size was $0.3-0.5 \mathrm{~kb}$ ). These results indicated that in the flanks of Alu of repeats, we might detect an enhanced TP53BP1 occupancy upon CGGBP1 depletion. We measured the difference in TP53BP1 occupancy (normalized CT-KD signals) in flanks of Alu, L1 and simple repeats genome-wide. We observed that in $\mathrm{KD}$, TP53BP1 binding was increased in the flanks of AluSINEs, LINEs and simple repeats genome-wide (Figure $3 \mathrm{C})$. These results showed that DNA repair is misdirected to repeat flanks in the absence of CGGBP1 which likely contributes to the short homology fusions that we have observed.

\section{DISCUSSION}

Chromosomal integrity is pivotal to eukaryotic genomes. In sexually reproducing dioecious taxa, each round of gametogenesis and fertilization generates new recombinants within the constraints of the genome volume and structure as defined by a set of homologous chromosome pairs. Gametic recombination and allelic assortment generate genetic diversity that provides the raw material for natural selection. Similarly, mitotically heritable somatic mutations generate diverse subpopulations of cells that undergo clonal evolution. Interestingly, such somatic mutations affect germline inheritance as well [21].

Many chromosomal rearrangements are in fact an outcome of error-prone repair of double strand breaks. Knowing the spectrum of somatic mosaicism at the level of chromosomal rearrangements is an important element in understanding the genome dynamics through time. The mosaic changes that happen early during development can even be lineage specific. Thus, the longer the somatic age of a cell and more the population doubling of a line, the more complex the somatic genotype landscape is expected to be [63]. Widespread loss of sex chromosomes in ageing somatic cells, especially chromosome $\mathrm{X}$ in females and $\mathrm{Y}$ in males have been described [64].

Somatic mosaicism due to randomly generated mutations is understood to be a fundamental cause for age-related cellular dysfunction and diseases such as neurodegeneration, reproductive problems and cancer. The net mutation load is a sum of mutations caused by environmental agents and endogenous mechanisms that damage as well as repair the DNA. The alterations in the DNA sequence are rectifiable as the complementary strand serves as a template for BER and NER pathways. The chimeric chromosomal events or chromosomal micro-mosaicism that we have studied here are apparently chromosomal fusion events captured in sequence reads. These chromosomal fusions are formed as an outcome of misdirected double strand repair processes and are not recognized and marked for repair like mismatch or other base changes. These chimeric chromosomes are rare events and can not be determined in the karyotype. The fate of such chimeric chromosomes is dependent on the non-neutrality of their effect on the cells. Thus, these alterations could either persist dormantly or become eliminated with the cells harboring them. Some of these chromosomal chimeras could even undergo clonal selection toward cellular transformation. DNA strand breaks are repaired through homology-directed repair mechanisms or non-homologous end-joining, both of which are error prone.

Alu repeats, the most populous of the repetitive elements in the human genome, present a great challenge to the fidelity of homology mediated repair $[65,66]$. Alus seed repair directed by sequence microhomology between Alus [67], similar to the short homology chimeric events that we have described. Similarly, L1 repeats induce double strand breaks, possibly through their endonuclease activity, and accelerate homology directed repair or NHEJ [68]. Recombination between Alu and L1 elements have also been reported [69]. Younger Alu subfamilies are reported to generate segmental duplications by homology directed strand break and DNA synthesis [69]. We too observed that in unstressed cells the chromosomal micromosaicism was rich mostly in younger Alu and L1 families with the older families showing only an increase after the heat stress.

An estimation of DNA sequence mosaicism is very error-prone. The genuine rare somatic variants could become contaminated with DNA sequence artifacts. However, the chromosomal chimera detection is free from such spurious sequence variations. Our strategy of detection of non-homologous interchromosomal chimeras is based on sequence alignment with length $0.2 \mathrm{~kb}$. Single base alterations caused by sequence artifacts would not affect the alignment of such long fragments to target regions in the genome. Additional curation of the data to remove any multiply-aligning reads further ensures that the calls for chimeric chromosomes are free of any errors. There are two attributes of our strategy which strengthen the identification of chimeras: First, the representation of chimeric regions by non-chimeric reads (A-A-A and B-B-B for the A-U-B) ensures that if there were no genuine chimeras, our approach would have classified them as non-chimeric reads. Second, a series of read fragments aligning to chromosomes $\mathrm{A}$ and $\mathrm{B}$ with a base-by-base incremental identification of the $U$ region is highly unlikely to be artefactual.

The homologous interallelic chimeras can be affected by point mutations. The rigorous curation steps as applied for detecting non-homologous chimeras were applied here as well. However, the MeDIP-seq data were obtained on the IonTorrent platform with shorter read lengths forcing us to use smaller $0.05 \mathrm{~kb}$ (instead of $0.2 \mathrm{~kb}$ ) fragments for chimera detections. However, even 
$0.05 \mathrm{~kb}$ fragments are long enough for high confidence unique alignments and the interchromosomal chimera frequencies calculated using this variation were still comparable to the ones obtained with $0.2 \mathrm{~kb}$ fragments. IonTorrent base call is of very high confidence [70] and when reinforced with conditions of parental genotypes in the same region and presence of non-chimeric reads representing the chimeric chromosome calls, the errors were minimized further. By comparing the disagreements between the parental and offspring genotypes we were able to work out the mutation (base change) frequency that was used for adjustment of interallelic chimera event rates for the mutation rates. However, the mutation rates were not different between $\mathrm{CT}$ and KD and hence would affect both $\mathrm{CT}$ and $\mathrm{KD}$ equally.

Knowing the level of chromosomal micromosaicism in cell culture is pivotal to understanding them as model systems. Fibroblasts and HEK293T are widely used cells. The chromosomal micro-mosaicism in these cells could help us understand the clonal drifts in their populations. This drift can have incalculable consequences on the population-averaged genotypes of cell lines when there are differences in culture conditions that act as stress additives to the background rates of chromosomal chimera formation. Interestingly, although largely the observed chimera frequencies were proportional to the length of different chromosomes, there were certain chromosomal pairs that showed a higher than expected chimera frequency with as well as without heat stress (such as chromosomes 14 and 22). Similarly, the frequency of chimeric DNA was much higher in HEK293T as compared to the fibroblasts. These findings suggest that the chimeric DNA frequency is a function of cell types. A more relevant calculation of expected chimera frequency will need to take into account the cell type-specific loads of endogenous DNA damage and repair and inherent epigenetics states, including chromatin topology and chromosomal proximity.

The interallelic chimeras are likely to cause a loss of heterozygosity which would unleash the effects of recessive somatic mutations at heterozygous loci. Since our variant call data are derived from a comparison between parental and offspring DNA sequences, our allelic identification is robust.

In the absence of heat stress, the $\mathrm{L} 1$ repeats are the primary sites for chromosomal chimera formation with a smaller contribution from the Alu and simple repeats. LINE repeats, a major component of the heterochromatin constitutes a larger fraction of the genome yet remains confined to a smaller volume fraction in the nuclear periphery $[71,72]$. L1 repeats face a higher molecular crowding [73]. The molecular crowding at the heterochromatin accelerates strand exchange and aberrant repair [74-76]. In growing cells, like DNA replication, DNA repair at the heterochromatic DNA is also delayed [77]. Cytosine methylation at mammalian specific M3 and
M4 L1 LINEs is decreased by CGGBP1 depletion [53]. Such a methylation change at L1 repeats can destabilize the genome through aberrant recombinations [41]. Upon heat stress, Alu repeats are transcriptionally activated. The presence of RNA is known to facilitate TP53BP1 association with damage and repair sites. TP53BP1 association with repeats could promote homologous recombination [78].

The results described here are important from multiple perspectives. Through these findings, we get an assessment of the rate at which chromosomal chimera exists in somatic cell cultures. Understanding somatic mutations and mosaicism has advanced our understanding of many diseases including cancer. These findings underscore the importance of the ignored sequence reads in the NGS datasets, often derived from cell cultures under experimental conditions that might be stressful to varying degrees. Changes in somatic mutation profile and scale as an effect of experimental interventions often go unreported. With more and more use of NGS in characterizing the genome and the epigenome, factoring in of such stable spontaneous mutations is key to a complete understanding of the sequence data.

The role of interspersed repeats, most prominently Alu and L1, in endogenous DNA damage is reported but their role in chromosomal micro-mosaicism has not been reported. Our results highlight the role of these repeats in generation of chimeric chromosomes, likely through sequence homology, that then involves DNA damage detection and repair as the repeat flanks are marked by TP53BP1. Because the activity of the repeats are different under conditions of stress, it is reasonable that we detect their differential enrichment in chimeras detected in the heat stressed samples.

Finally, this description of chromosomal micromosaicism shows that the protein CGGBP1 levels keep it in check. Depletion of CGGBP1 enhanced the mosaic chromosomal frequency to levels comparable to those of heat stress. CGGBP1 is a gene that shows a heat shock protein-like spike in transcription along with a strong nuclear presence upon acute heat shock. It cooperates with transcription factor NFIX and the high mobility group protein HMGN1 for a proper HSF1 transcription induction upon heat shock. This regulation of heat shock response by CGGBP1 could trick the cells into a heat stress-like state. Thus heat stress and CGGBP1 depletion both could generate similar effects of chromosomal instability thereby inducing strand breaks and repairs though end-ligations. CGGBP1 loss-of-function leads to chromosomal fusions through a mechanism that involves telomere deprotection [55] and the effects mimic breakage-fusion mechanisms of chromosomal fusions typical of cells in crisis. The cells used in this study are low passage primary cells which are not expected to display any chromosomal instabilities. The GM01391 cells are from a subject affected by Hurler syndrome whereas the GM02639 are from a normal 
subject whose siblings are affected by juvenile-onset insulin-dependent diabetes. Our experiments are based on the premise that these diseases do not affect the chimeric DNA generation rate. Also, the usage of matched controls eliminates any biases in chimera frequency calculation due to these disease states. Expectedly, these fibroblast lines do not exhibit any senescence-associated crisis like genome instability and we did not observe any prevalence of telomeric or sub-telomeric repeats in the chimeric reads. The telomeric fusions between the chromosomes are expected to have much longer repeat tracts than the length of our read bins $(0.2 \mathrm{~kb})$. The fusions observed here however do have a significant contribution of satellite repeats through short sequence homologies across nonhomologous chromosomes that might facilitate strand invasions. The other repeats that are enriched in the chimeric DNA identified in this study include the Alu and L1 retrotransposons. As discussed above, these repeats are numerous and strong candidates to generate chimeric chromosomes through short homology-directed end-joining. Interestingly, CGGBP1 regulates both these repeat types. CGGBP1 is required for proper cytosine methylation and inactivation of $\mathrm{L} 1$ and Alu repeats. CGGBP1 depletion activates Alu SINEs in a manner that is similar to Alu induction by heat shock. Thus, CGGBP1 depletion and heat shock could increase the Alu-mediated chimera formation through overlapping mechanisms. Similarly, CGGBP1 is required for proper cytosine methylation and $\mathrm{H} 3 \mathrm{~K} 9 \mathrm{me} 3$ signals at $\mathrm{L} 1$ repeats. It is possible that the loss of CTCF-binding at L1 repeats upon CGGBP1 depletion unpacks the chromatin loops thereby easing the strand invasions across different L1 elements. An expected effect of such an epigenetic disruption is generation of chimeric chromosomes in the neighbourhood of $\mathrm{L} 1$ repeats. The presence of TP53BP1 in the flanks of these repeats upon CGGBP1 depletion reinforces the idea that a genuine DNA strand break and an impending repair in repeat flanks generates the chimeric DNA that we discover as chromosomal micro-mosaicism. It is likely that additional mechanisms cooperate with stress response and proteins like CGGBP1 to modulate the rate at which chimeric chromosomes emerge in somatic cells.

Our findings are of importance to the vast area of cancer biology research wherein a host of cell lines are routinely employed. The findings presented here inform us about chromosomal chimeras in cultured cells, their generation due to stress and deregulation of genomic repeats and provide a knowledge background in which we shall interpret the results obtained from cultures cell systems. Cellular heterogeneity in tumorigenesis is the basis of clonal evolution of tumors and is a critical component of cancer cell biology. The mechanisms we report here could evidently apply with some variations to somatic cells in vivo thus implicating repeat deregulation and stress with somatic mosaicism and diseases, including cancer. The lasting impact of the chimeric events we have reported is understandable as these are chromosomal fusion events which are likely an outcome of misdirected DNA end-joining, unrectifiable and subject to selection or elimination. Finally, our results reinforce the fact that chromosomal chimera formation can take place in cells with intact canonical checkpoint mechanisms. These chimeric events thus have the potential to precede the oncogenic transformation of cells with causal effects on cell fate.

\section{MATERIALS AND METHODS}

\section{Cell culture, heat shock, genomic DNA isolation and Nanopore sequencing}

Human primary fibroblasts GM02639 (Coriell cell repository) at passage number 16 and HEK293T-CT and -KD were cultured in DMEM as described before $[49,53]$.

For the heat stress and recovery experiments using GM02639, the increase in temperature from $37^{\circ} \mathrm{C}$ to $40^{\circ} \mathrm{C}$ was done through acclimatization of cells progressively at $38^{\circ} \mathrm{C}, 39^{\circ} \mathrm{C}$ and $40^{\circ} \mathrm{C}$ for $24 \mathrm{~h}$ each. After each round of heat stress, cells were either reverted to $37^{\circ} \mathrm{C}$ for $24 \mathrm{~h}$ for recovery before harvesting them for DNA extraction or cultured at a $1^{\circ} \mathrm{C}$ higher temperature. The temperature for heat stress experiments were established by identifying the maximum tolerated temperature at which these cells could be cultured without any visible loss of cell adhesion and death at $40^{\circ} \mathrm{C}$ as well as after recovery. Using this method the heat stress temperatures of $41^{\circ} \mathrm{C}$ and $42^{\circ} \mathrm{C}$ showed evidence of cell detachment and death upon recovery.

For HEK293T-CT and -KD, the cells were directly subjected to heat stress and at $42^{\circ} \mathrm{C}$ for $24 \mathrm{~h}$ the cells could be recovered at $37^{\circ} \mathrm{C}$ with visible cell death.

Genomic DNA for GM02639, HEK293T-CT and HEK293T-KD were extracted as described before [53]. Briefly, the cells are harvested from (i) two T25 flasks (for GM02639) and (ii) two $100 \mathrm{~mm}$ dishes (each for HEK293T$\mathrm{CT}$ and $-\mathrm{KD}$ at different temperature set points). The cells were lysed using cell lysis buffer $(10 \mathrm{mM}$ Tris $\mathrm{pH} 8.0$, $100 \mathrm{mM} \mathrm{NaCl}, 25 \mathrm{mM}$ EDTA and $0.5 \% \mathrm{SDS} \mathrm{v} / \mathrm{v})$ and $2 \mu \mathrm{l}$ of $10 \mathrm{mg} / \mathrm{ml}$ Proteinase K (P2308; Sigma). The genomic DNA were isolated using phenol:chloroform:isoamyl alcohol (in 25:24:1 ratio) method followed by ethanol precipitation at $-20^{\circ} \mathrm{C}$ overnight. The DNA was dissolved in nuclease-free water and stored in $-20^{\circ} \mathrm{C}$.

Nanopore sequencing libraries were prepared using the Ligation Sequencing Kit (SQK-LSK109; Oxford Nanopore Technologies) and sequenced on MinION (Mk1B) using FLO-MIN106 flowcells as per the instructions of the manufacturer. $1 \mu \mathrm{g}$ of DNA was used as input for nick ligation and end repair.

Using Agencourt AMPure XP beads, DNA fragments were purified and the manufacturer's Short Fragment Buffer (SFB) was used to enrich adaptor-ligated DNA fragments of all size ranges. After sequencing adaptor 
ligation, sequencing was performed for $\sim 48 \mathrm{~h}$ using realtime base calling using Guppy through MinKnow.

\section{Methyl(cytosine) DNA immunoprecipitation (MeDIP), sequencing of MeDIP libraries and genomic DNA}

MeDIP was performed exactly for GM01391 as described earlier [53]. MeDIP data was already available for GM02639 [53]. The sequencing library for GM01391 and genomic DNA libraries for parents (GM01392 and GM01393) were generated according to the protocol mentioned earlier [49]. The Ion Torrent S5 sequencer was used as the sequencing platform. Using the plugin "FilterDuplicates" in IonTorrent Suite the sequenced reads were filtered to remove poly-clonals and PCR readduplicates.

\section{Sequence data analysis}

Sequences were acquired (MinKNOW and Guppy basecaller, ONT), subjected to adapter trimming by Porechop. Sequences from genomic DNA and MeDIP were split into $0.2 \mathrm{~kb}$ and $0.05 \mathrm{~kb}$ bins respectively and subjected to end-to-end alignment by bowtie2. For sequence and genomic coordinate manipulations, samtools and bedtools were used. Data was compiled using LibreOffice Spreadsheet and graphs were plotted using deepTools or Prism 9 (GraphPad).

\section{Interchromosomal chimera detection}

Reads of at least $600 \mathrm{bp}$ and $150 \mathrm{bp}$ of length were used to identify chimera in heat stress and MeDIP samples respectively. The reads which had only one $0.2 \mathrm{~kb}$ and $0.05 \mathrm{~kb}$ bin unmapped ( $\mathrm{U}$ bin) were filtered out after the alignment in heat stress or genomic DNA and MeDIP or parental genomic DNA respectively. The flanks of the $\mathrm{U}$ bin represent two non-homologous chromosomes (for example chromosomes A and B) such that each flank continues to carry the respective chromosome profile. The A-U-B chimeric reads were further splitted into $0.2 \mathrm{~kb}$ bins with one base sliding window using EMBOSS splitter with the options -size 200 -overlap 199.

\section{Variant calling and allelic identity establishment}

The BAM outputs of the mapped reads were first subjected to generate genotype likelihood individually by bcftools mpileup. The variants were called by using bcftools call with the options -c and --skip-variants 'INDELS'. The corresponding records or variants at the same genomic positions were identified in the MeDIP sample in an order (offspring, mother and father) using bcftools isec with the options $-\mathrm{c}$ all $-\mathrm{n}+3$. The allelic identity for offspring at a given location was established by filtering for the genomic positions and its genotypic information by using bcftools query, followed by offsprings' (GM02639 and GM01391) genotype conferred by only one of the parents.

\section{TP53BP1 ChIP-sequencing and data analysis}

ChIP-sequencing was performed exactly as described earlier [49] using TP53BP1 antibody (NB100304; Novus Biologicals). Briefly, the cells were crosslinked using $4 \%$ formaldehyde solution at $37^{\circ} \mathrm{C}$ for 10 min followed by quenching with $125 \mathrm{mM}$ glycine. The cross-linked cells were washed with PBS, harvested and resuspended in an SDS lysis buffer containing $1 \mathrm{X}$ protease inhibitor. The cells were lysed on ice for 30 min with intermittent tapping. This was followed by sonication using a Diagenode bioruptor for 30 cycles set at $30 \mathrm{~s}$ on and $30 \mathrm{~s}$ off. The mean fragment length was standardised to $150 \pm 50 \mathrm{bp}$. Sonicated lysates were cleared by centrifugation and were incubated overnight at $4{ }^{\circ} \mathrm{C}$ with antibody-conjugated beads. The beads were washed with IP wash buffers. The cross-links were removed in a reverse cross-linking buffer followed by Proteinase $\mathrm{K}$ digestion at $65^{\circ} \mathrm{C}$ for $15 \mathrm{~min}$. Reverse crosslinked DNA was purified by DNA purification magnetic beads and used for library preparation and sequencing on the Ion Torrent S5 sequencing platform. The TP53BP1ChIP sequence reads were filtered for read duplicates and read quality score (Q20) using the built-in options in IonTorrent suite. The quality filtered reads were subjected to end-to-end alignment on hg38. The aligned reads were either subjected to estimate genome-wide distribution at $0.2 \mathrm{~kb}$ bins using bedtools coverage with at least $50 \%$ read overlaps or used to calculate the difference of normalised signal from HEK293T-CT to HEK293T-KD using deepTools bamCompare with the option subtract followed by plotting the signal difference at different repeat flanks genome-wide. The data analysis pipeline for TP53BP1 ChIP-seq is described in the results section.

\section{Author contributions}

SD, MP, DP performed the experiments, SD, MP, SK analyzed the data, US supervised the work. SD, MP and US wrote the manuscript.

\section{ACKNOWLEDGMENTS}

The authors duly acknowledge the Coriell cell repository for the fibroblasts used in this study and NCCS Pune for HEK293T cells.

\section{CONFLICTS OF INTEREST}

Authors have no conflicts of interest to declare. 


\section{FUNDING}

US received support from DST-ICPS (T-357) and DBT (BT/PR15883/BRB/10/1480/2016). The studentships of SD and SK were supported by MHRD, Government of India; MP and DP were supported by UGC-NET JRF.

\section{REFERENCES}

1. Fernández LC, Torres M, Real FX. Somatic mosaicism: on the road to cancer. Nat Rev Cancer. 2016; 16:43-55. https:// doi.org/10.1038/nrc.2015.1. [PubMed]

2. Mkrtchyan H, Gross M, Hinreiner S, Polytiko A, Manvelyan M, Mrasek K, Kosyakova N, Ewers E, Nelle H, Liehr T, Bhatt S, Thoma K, Gebhart E, et al. The human genome puzzle - the role of copy number variation in somatic mosaicism. Curr Genomics. 2010; 11:426-31. https://doi. org/10.2174/138920210793176047. [PubMed]

3. Dou Y, Gold HD, Luquette LJ, Park PJ. Detecting Somatic Mutations in Normal Cells. Trends Genet. 2018; 34:545-57. https://doi.org/10.1016/j.tig.2018.04.003. [PubMed]

4. Thorpe J, Osei-Owusu IA, Avigdor BE, Tupler R, Pevsner J. Mosaicism in Human Health and Disease. Annu Rev Genet. 2020; 54:487-510. https://doi.org/10.1146/annurevgenet-041720-093403. [PubMed]

5. Dou Y, Kwon M, Rodin RE, Cortés-Ciriano I, Doan R, Luquette LJ, Galor A, Bohrson C, Walsh CA, Park PJ. Accurate detection of mosaic variants in sequencing data without matched controls. Nat Biotechnol. 2020; 38:314 19. https://doi.org/10.1038/s41587-019-0368-8. [PubMed]

6. Kim B, Won D, Jang M, Kim H, Choi JR, Kim TI, Lee ST. Next-generation sequencing with comprehensive bioinformatics analysis facilitates somatic mosaic APC gene mutation detection in patients with familial adenomatous polyposis. BMC Med Genomics. 2019; 12:103. https://doi. org/10.1186/s12920-019-0553-0. [PubMed]

7. Narisu N, Rothwell R, Vrtačnik P, Rodríguez S, Didion J, Zöllner S, Erdos MR, Collins FS, Eriksson M. Analysis of somatic mutations identifies signs of selection during in vitro aging of primary dermal fibroblasts. Aging Cell. 2019; 18:e13010. https://doi.org/10.1111/acel.13010. [PubMed]

8. Heng HH. Missing heritability and stochastic genome alterations. Nat Rev Genet. 2010; 11:813. https://doi. org/10.1038/nrg2809-c3. [PubMed]

9. Heng HH, Liu G, Stevens JB, Abdallah BY, Horne SD, Ye KJ, Bremer SW, Chowdhury SK, Ye CJ. Karyotype heterogeneity and unclassified chromosomal abnormalities. Cytogenet Genome Res. 2013; 139:144-57. https://doi. org/10.1159/000348682. [PubMed]

10. Sebat J, Lakshmi B, Troge J, Alexander J, Young J, Lundin P, Månér S, Massa H, Walker M, Chi M, Navin N, Lucito $\mathrm{R}$, Healy J, et al. Large-scale copy number polymorphism in the human genome. Science. 2004; 305:525-28. https:// doi.org/10.1126/science.1098918. [PubMed]
11. Jacobs KB, Yeager M, Zhou W, Wacholder S, Wang Z, Rodriguez-Santiago B, Hutchinson A, Deng X, Liu C, Horner MJ, Cullen M, Epstein CG, Burdett L, et al. Detectable clonal mosaicism and its relationship to aging and cancer. Nat Genet. 2012; 44:651-58. https://doi. org/10.1038/ng.2270. [PubMed]

12. Gibson J, Morton NE, Collins A. Extended tracts of homozygosity in outbred human populations. Hum Mol Genet. 2006; 15:789-95. https://doi.org/10.1093/hmg/ ddi493. [PubMed]

13. Simon-Sanchez J, Scholz S, Fung HC, Matarin M, Hernandez D, Gibbs JR, Britton A, de Vrieze FW, Peckham E, Gwinn-Hardy K, Crawley A, Keen JC, Nash J, et al. Genome-wide SNP assay reveals structural genomic variation, extended homozygosity and cell-line induced alterations in normal individuals. Hum Mol Genet. 2007; 16:1-14. https://doi.org/10.1093/hmg/ddl436. [PubMed]

14. Žilina O, Koltšina M, Raid R, Kurg A, Tõnisson N, Salumets A. Somatic mosaicism for copy-neutral loss of heterozygosity and DNA copy number variations in the human genome. BMC Genomics. 2015; 16:703. https://doi. org/10.1186/s12864-015-1916-3. [PubMed]

15. De S. Somatic mosaicism in healthy human tissues. Trends Genet. 2011; 27:217-23. https://doi.org/10.1016/j. tig.2011.03.002. [PubMed]

16. Vorsanova SG, Yurov YB, Iourov IY. Dynamic nature of somatic chromosomal mosaicism, genetic-environmental interactions and therapeutic opportunities in disease and aging. Mol Cytogenet. 2020; 13:16. https://doi.org/10.1186/ s13039-020-00488-0. [PubMed]

17. Stevens JB, Abdallah BY, Liu G, Ye CJ, Horne SD, Wang G, Savasan S, Shekhar M, Krawetz SA, Hüttemann M, Tainsky MA, Wu GS, Xie Y, et al. Diverse system stresses: common mechanisms of chromosome fragmentation. Cell Death Dis. 2011; 2:e178. https://doi.org/10.1038/cddis.2011.60. [PubMed]

18. Horne SD, Chowdhury SK, Heng HH. Stress, genomic adaptation, and the evolutionary trade-off. Front Genet. 2014; 5:92. https://doi.org/10.3389/fgene.2014.00092. [PubMed]

19. Liu G, Stevens JB, Horne SD, Abdallah BY, Ye KJ, Bremer SW, Ye CJ, Chen DJ, Heng HH. Genome chaos: survival strategy during crisis. Cell Cycle. 2014; 13:528-37. https:// doi.org/10.4161/cc.27378. [PubMed]

20. Kültz D. Molecular and evolutionary basis of the cellular stress response. Annu Rev Physiol. 2005; 67:225-57. https://doi. org/10.1146/annurev.physiol.67.040403.103635. [PubMed]

21. Iourov IY, Vorsanova SG, Yurov YB, Kutsev SI. Ontogenetic and Pathogenetic Views on Somatic Chromosomal Mosaicism. Genes (Basel). 2019; 10:379. https://doi.org/10.3390/genes10050379. [PubMed]

22. Yeaman S. Genomic rearrangements and the evolution of clusters of locally adaptive loci. Proc Natl Acad Sci U S A. 2013; 110:E1743-51. https://doi.org/10.1073/ pnas.1219381110. [PubMed] 
23. Henry KA, Blank HM, Hoose SA, Polymenis M. The unfolded protein response is not necessary for the $\mathrm{G} 1 / \mathrm{S}$ transition, but it is required for chromosome maintenance in Saccharomyces cerevisiae. PLoS One. 2010; 5:e12732. https://doi.org/10.1371/journal.pone.0012732. [PubMed]

24. Kantidze OL, Velichko AK, Luzhin AV, Razin SV. Heat Stress-Induced DNA Damage. Acta Naturae. 2016; 8:7578. [PubMed]

25. Paul C, Melton DW, Saunders PT. Do heat stress and deficits in DNA repair pathways have a negative impact on male fertility? Mol Hum Reprod. 2008; 14:1-8. https://doi. org/10.1093/molehr/gam089. [PubMed]

26. Purschke M, Laubach HJ, Anderson RR, Manstein D. Thermal injury causes DNA damage and lethality in unheated surrounding cells: active thermal bystander effect. J Invest Dermatol. 2010; 130:86-92. https://doi. org/10.1038/jid.2009.205. [PubMed]

27. Velichko AK, Petrova NV, Kantidze OL, Razin SV. Dual effect of heat shock on DNA replication and genome integrity. Mol Biol Cell. 2012; 23:3450-60. https://doi. org/10.1091/mbc.E11-12-1009. [PubMed]

28. Tan Z, Chan YJA, Chua YJK, Rutledge SD, Pavelka N, Cimini D, Rancati G. Environmental stresses induce karyotypic instability in colorectal cancer cells. Mol Biol Cell. 2019; 30:42-55. https://doi.org/10.1091/mbc.E18-100626. [PubMed]

29. Wang Y, Guan J, Wang H, Wang Y, Leeper D, Iliakis G. Regulation of dna replication after heat shock by replication protein a-nucleolin interactions. J Biol Chem. 2001; 276:20579-88. https://doi.org/10.1074/jbc.M100874200. [PubMed]

30. Roti Roti JL. Heat-induced alterations of nuclear protein associations and their effects on DNA repair and replication. Int J Hyperthermia. 2007; 23:3-15. https://doi. org/10.1080/02656730601091759. [PubMed]

31. Li S, Wu X. Common fragile sites: protection and repair. Cell Biosci. 2020; 10:29. https://doi.org/10.1186/s13578020-00392-5. [PubMed]

32. Takahashi A, Mori E, Nakagawa Y, Kajihara A, Kirita T, Pittman DL, Hasegawa M, Ohnishi T. Homologous recombination preferentially repairs heat-induced DNA double-strand breaks in mammalian cells. Int J Hyperthermia. 2017; 33:336-42. https://doi.org/10.1080/0 2656736.2016.1252989. [PubMed]

33. Guirouilh-Barbat J, Lambert S, Bertrand P, Lopez BS. Is homologous recombination really an error-free process? Front Genet. 2014; 5:175. https://doi.org/10.3389/ fgene.2014.00175. [PubMed]

34. Genet SC, Fujii Y, Maeda J, Kaneko M, Genet MD, Miyagawa K, Kato TA. Hyperthermia inhibits homologous recombination repair and sensitizes cells to ionizing radiation in a time- and temperature-dependent manner. $\mathrm{J}$ Cell Physiol. 2013; 228:1473-81. https://doi.org/10.1002/ jcp.24302. [PubMed]
35. Laszlo A, Fleischer I. Heat-induced perturbations of DNA damage signaling pathways are modulated by molecular chaperones. Cancer Res. 2009; 69:2042-49. https://doi. org/10.1158/0008-5472.CAN-08-1639. [PubMed]

36. Youssoufian H, Pyeritz RE. Mechanisms and consequences of somatic mosaicism in humans. Nat Rev Genet. 2002; 3:748-58. https://doi.org/10.1038/nrg906. [PubMed]

37. McVean $\mathrm{G}$. What drives recombination hotspots to repeat DNA in humans? Philos Trans R Soc Lond B Biol Sci. 2010; 365:1213-18. https://doi.org/10.1098/rstb.2009.0299. [PubMed]

38. Lesecque Y, Glémin S, Lartillot N, Mouchiroud D, Duret L. The red queen model of recombination hotspots evolution in the light of archaic and modern human genomes. PLoS Genet. 2014; 10:e1004790. https://doi.org/10.1371/journal. pgen.1004790. [PubMed]

39. Giordano M, Infantino L, Biggiogera M, Montecucco A, Biamonti G. Heat Shock Affects Mitotic Segregation of Human Chromosomes Bound to Stress-Induced Satellite III RNAs. Int J Mol Sci. 2020; 21:2812. https://doi. org/10.3390/ijms21082812. [PubMed]

40. Yang F, Wang PJ. Multiple LINEs of retrotransposon silencing mechanisms in the mammalian germline. Semin Cell Dev Biol. 2016; 59:118-25. https://doi.org/10.1016/j. semcdb.2016.03.001. [PubMed]

41. Zamudio N, Barau J, Teissandier A, Walter M, Borsos M, Servant N, Bourc'his D. DNA methylation restrains transposons from adopting a chromatin signature permissive for meiotic recombination. Genes Dev. 2015; 29:1256-70. https://doi.org/10.1101/gad.257840.114. [ubMed]

42. Chen RZ, Pettersson U, Beard C, Jackson-Grusby L, Jaenisch R. DNA hypomethylation leads to elevated mutation rates. Nature. 1998; 395:89-93. https://doi. org/10.1038/25779. [ [PubMed]

43. Bird A. DNA methylation patterns and epigenetic memory. Genes Dev. 2002; 16:6-21. https://doi. org/10.1101/gad.947102. [PubMed]

44. Goll MG, Bestor TH. Eukaryotic cytosine methyltransferases. Annu Rev Biochem. 2005; 74:481-514. https://doi.org/10.1146/annurev.biochem.74.010904.153721. [PubMed]

45. Polak P, Arndt PF. Transcription induces strand-specific mutations at the 5' end of human genes. Genome Res. 2008; 18:1216-23. https://doi.org/10.1101/gr.076570.108. [PubMed]

46. Polak P, Arndt PF. Long-range bidirectional strand asymmetries originate at $\mathrm{CpG}$ islands in the human genome. Genome Biol Evol. 2009; 1:189-97. https://doi. org/10.1093/gbe/evp024. [PubMed]

47. Auton A, Fledel-Alon A, Pfeifer S, Venn O, Ségurel L, Street T, Leffler EM, Bowden R, Aneas I, Broxholme J, Humburg P, Iqbal Z, Lunter G, et al. A fine-scale chimpanzee genetic map from population sequencing. Science. 2012; 336:19398. https://doi.org/10.1126/science.1216872. [PubMed] 
48. Aguilera A, García-Muse T. R loops: from transcription byproducts to threats to genome stability. Mol Cell. 2012; 46:115-24. https://doi.org/10.1016/j.molcel.2012.04.009. [PubMed]

49. Patel D, Patel M, Datta S, Singh U. CGGBP1 regulates CTCF occupancy at repeats. Epigenetics Chromatin. 2019; 12:57. https://doi.org/10.1186/s13072-019-0305-6. [PubMed]

50. Patel D, Patel M, Westermark B, Singh U. Dynamic bimodal changes in $\mathrm{CpG}$ and non- $\mathrm{CpG}$ methylation genome-wide upon CGGBP1 loss-of-function. BMC Res Notes. 2018; 11:419. https://doi.org/10.1186/s13104-0183516-1. [PubMed]

51. Agarwal P, Collier P, Fritz MH, Benes V, Wiklund HJ, Westermark B, Singh U. CGGBP1 mitigates cytosine methylation at repetitive DNA sequences. BMC Genomics. 2015; 16:390. https://doi.org/10.1186/s12864-015-1593-2. [PubMed]

52. Agarwal P, Enroth S, Teichmann M, Jernberg Wiklund H, Smit A, Westermark B, Singh U. Growth signals employ CGGBP1 to suppress transcription of Alu-SINEs. Cell Cycle. 2016; 15:1558-71. https://doi.org/10.4161/1538410 1.2014.967094. [PubMed]

53. Patel M, Patel D, Datta S, Singh U. CGGBP1-regulated cytosine methylation at CTCF-binding motifs resists stochasticity. BMC Genet. 2020; 21:84. https://doi. org/10.1186/s12863-020-00894-8. [PubMed]

54. Patel D, Patel M, Datta S, Singh U. CGGBP1-dependent CTCF-binding sites restrict ectopic transcription. Cell Cycle. 2021; 20:2387-401. https://doi.org/10.1080/153841 01.2021.1982508. [PubMed]

55. Singh U, Maturi V, Jones RE, Paulsson Y, Baird DM, Westermark B. CGGBP1 phosphorylation constitutes a telomere-protection signal. Cell Cycle. 2014; 13:96-105. https://doi.org/10.4161/cc.26813. [PubMed]

56. Singh U, Westermark B. CGGBP1--an indispensable protein with ubiquitous cytoprotective functions. Ups J Med Sci. 2015; 120:219-32. https://doi.org/10.3109/03009734.2 015.1086451. [PubMed]

57. Singh U, Bongcam-Rudloff E, Westermark B. A DNA sequence directed mutual transcription regulation of HSF 1 and NFIX involves novel heat sensitive protein interactions. PLoS One. 2009; 4:e5050. https://doi.org/10.1371/journal. pone.0005050. [ [PubMed]

58. Tate JG, Bamford S, Jubb HC, Sondka Z, Beare DM, Bindal N, Boutselakis H, Cole CG, Creatore C, Dawson E, Fish P, Harsha B, Hathaway C, et al. COSMIC: the Catalogue Of Somatic Mutations In Cancer. Nucleic Acids Res. 2019; 47:D941-47. https://doi.org/10.1093/nar/gky1015. [PubMed]

59. Hahn Y, Bera TK, Gehlhaus K, Kirsch IR, Pastan IH, Lee B. Finding fusion genes resulting from chromosome rearrangement by analyzing the expressed sequence databases. Proc Natl Acad Sci U S A. 2004; 101:13257-61. https://doi.org/10.1073/pnas.0405490101. [PubMed]
60. Kim P, Zhou X. FusionGDB: fusion gene annotation DataBase. Nucleic Acids Res. 2019; 47:D994-1004. https:// doi.org/10.1093/nar/gky1067. [PubMed]

61. Mitelman Database Chromosome Aberrations and Gene Fusions in Cancer. 2021. Available 2021 Oct 6, from https:// mitelmandatabase.isb-cgc.org

62. Mirman Z, de Lange T. 53BP1: a DSB escort. Genes Dev. 2020; 34:7-23. https://doi.org/10.1101/gad.333237.119. [PubMed]

63. Mkrtchyan $\mathrm{H}$, Gross $\mathrm{M}$, Hinreiner S, Polytiko A, Manvelyan M, Mrasek K, Kosyakova N, Ewers E, Nelle H, Liehr T, Volleth M, Weise A. Early embryonic chromosome instability results in stable mosaic pattern in human tissues. PLoS One. 2010; 5:e9591. https://doi.org/10.1371/journal. pone.0009591. [PubMed]

64. Ouseph MM, Hasserjian RP, Dal Cin P, Lovitch SB, Steensma DP, Nardi V, Weinberg OK. Genomic alterations in patients with somatic loss of the $\mathrm{Y}$ chromosome as the sole cytogenetic finding in bone marrow cells. Haematologica. 2021; 106:555-64. https://doi.org/10.3324/ haematol.2019.240689. [PubMed]

65. Morales ME, White TB, Streva VA, DeFreece CB, Hedges DJ, Deininger PL. The contribution of alu elements to mutagenic DNA double-strand break repair. PLoS Genet. 2015; 11:e1005016. https://doi.org/10.1371/journal. pgen.1005016. [PubMed]

66. Kitada K, Aikawa S, Aida S. Alu-Alu fusion sequences identified at junction sites of copy number amplified regions in cancer cell lines. Cytogenet Genome Res. 2013; 139:1-8. $\quad$ https://doi.org/10.1159/000342885. [PubMed]

67. Elliott B, Richardson C, Jasin M. Chromosomal translocation mechanisms at intronic alu elements in mammalian cells. Mol Cell. 2005; 17:885-94. https://doi. org/10.1016/j.molcel.2005.02.028. [PubMed]

68. Gasior SL, Wakeman TP, Xu B, Deininger PL. The human LINE-1 retrotransposon creates DNA doublestrand breaks. J Mol Biol. 2006; 357:1383-93. https://doi. org/10.1016/j.jmb.2006.01.089. [PubMed]

69. Beck CR, Garcia-Perez JL, Badge RM, Moran JV. LINE-1 elements in structural variation and disease. Annu Rev Genomics Hum Genet. 2011; 12:187-215. https://doi.org/10.1146/annurev-genom-082509-141802. [PubMed]

70. Loman NJ, Misra RV, Dallman TJ, Constantinidou C, Gharbia SE, Wain J, Pallen MJ. Performance comparison of benchtop high-throughput sequencing platforms. Nat Biotechnol. 2012; 30:434-39. https://doi.org/10.1038/ nbt.2198. [PubMed]

71. Daban JR. Physical constraints in the condensation of eukaryotic chromosomes. Local concentration of DNA versus linear packing ratio in higher order chromatin structures. Biochemistry. 2000; 39:3861-66. https://doi. org/10.1021/bi992628w. [PubMed] 
72. Bohrmann B, Haider M, Kellenberger E. Concentration evaluation of chromatin in unstained resin-embedded sections by means of low-dose ratio-contrast imaging in STEM. Ultramicroscopy. 1993; 49:235-51. https://doi. org/10.1016/0304-3991(93)90230-u. [PubMed]

73. Bancaud A, Huet S, Daigle N, Mozziconacci J, Beaudouin J, Ellenberg J. Molecular crowding affects diffusion and binding of nuclear proteins in heterochromatin and reveals the fractal organization of chromatin. EMBO J. 2009; 28:3785-98. https://doi.org/10.1038/emboj.2009.340. [PubMed]

74. Feng B, Frykholm K, Nordén B, Westerlund F. DNA strand exchange catalyzed by molecular crowding in PEG solutions. Chem Commun (Camb). 2010; 46:8231-33. https://doi.org/10.1039/c0cc03117h. [PubMed]

75. Richter K, Nessling M, Lichter P. Experimental evidence for the influence of molecular crowding on nuclear architecture. J Cell Sci. 2007; 120:1673-80. https://doi. org/10.1242/jcs.03440. [PubMed]
76. Cravens SL, Schonhoft JD, Rowland MM, Rodriguez AA, Anderson BG, Stivers JT. Molecular crowding enhances facilitated diffusion of two human DNA glycosylases. Nucleic Acids Res. 2015; 43:4087-97. https://doi. org/10.1093/nar/gkv301. [PubMed]

77. Natale F, Scholl A, Rapp A, Yu W, Rausch C, Cardoso MC. DNA replication and repair kinetics of Alu, LINE-1 and satellite III genomic repetitive elements. Epigenetics Chromatin. 2018; 11:61. https://doi.org/10.1186/s13072018-0226-9. [PubMed]

78. Tang J, Cho NW, Cui G, Manion EM, Shanbhag NM, Botuyan MV, Mer G, Greenberg RA. Acetylation limits 53BP1 association with damaged chromatin to promote homologous recombination. Nat Struct Mol Biol. 2013; 20:317-25. https://doi.org/10.1038/nsmb.2499. [PubMed] 